Library of Derivatizable Multiblock Copolymers by Nucleophilic Substitution Polymerization and Targeting Specific Properties

Bhingaradiya Nutan, Avinash Kumar and Suresh K. Jewrajka*

Membrane Science and Separation Technology Division, Central Salt and Marine Chemicals

Research Institute (CSIR-CSMCRI), G. B. Marg, Bhavnagar, Gujarat 364002, India

Academy of Scientific and Innovative Research (AcSIR), Ghaziabad-201002, India

Corresponding author: Suresh K. Jewrajka

Email: skjewrajka@csmcri.res.in 


\section{Gel Permeation Chromatography (GPC)}

GPC analysis of the MBCs was performed using a separation module (Waters Model 2695) coupled with Waters 2414 refractive index detector and Styragel columns (HR 0.5 DMF, HR 4E DMF, and HR 5 DMF). DMF (HPLC grade, Spectrochem, India) containing $0.1 \% \mathrm{w} / \mathrm{v} \mathrm{LiBr}$ was used as eluent at a flow rate of $0.8 \mathrm{~mL} / \mathrm{min}$ at $25{ }^{\circ} \mathrm{C}$. Different poly(styrene) standard samples were used for calibration. Empower2 Software was used for the analysis of the data. Data were manually extracted from the traces and then plotted using Origin software.

\section{Determination of Stability of the Self-assemblies of MBCs by Pyrene Encapsulation and}

\section{Release Experiments}

The stability of the self-assemblies of MBCs was determined by monitoring the release of pyrene from them. Pyrene loading was performed as follows. ${ }^{1,2,3,4}$ Stock solution of pyrene (3 $\mathrm{mL}, 2 \mathrm{mg} / \mathrm{mL}$ ) in DCM was transferred into a flask and the DCM was evaporated by rotary evaporator. A solution of MBC ( $1 \mathrm{~mL}, 6 \mathrm{mg} / \mathrm{mL})$ was prepared in DMF and was added into the above pyrene stock solution. Next, PBS ( $\mathrm{pH} 7.4,0.1 \mathrm{M}, 5 \mathrm{~mL}$ ) was added into the solution of MBC and pyrene for about 20 min with continuous stirring. After addition, the mixture was allowed to stir for another 1h. The pyrene loaded mixture was dialysed (MWCO $2000 \mathrm{Da})$ against PBS ( $\mathrm{pH} \mathrm{7.4)} \mathrm{for} 48 \mathrm{~h}$. The outer solution was changed at the interval of $6 \mathrm{~h}$. The dialysed solution was filtered to remove insoluble pyrene. Pyrene loading was determined by the UV-Visible spectroscopy. Standard calibration curves of pyrene in different solvents were used depending on the $\mathrm{I}_{1} / \mathrm{I}_{3}$ values of pyrene in the micelles of different copolymers. ${ }^{4,5,6}$ Pyrene loading content was calculated by the following equation:

$$
\text { Loading content }=\frac{\text { weight of loaded pyrene }}{\text { weight of } \mathrm{MBC}} \times 100 \%
$$

Cumulative release of pyrene was determined to check the stability of the selfassemblies, and the efficacy towards controlled release of hydrophobic guest molecules. The 
pyrene loaded solution (PBS) of the copolymer $(20 \mathrm{~mL})$ was taken in glass vials. The $\mathrm{pH}$ of the solution was adjusted to 7.4 and 5 respectively. The glass vials were kept in an incubator shaker (INFORS AGCH-4103) at temperature of $37{ }^{\circ} \mathrm{C}$ and at a shaking speed of $100 \mathrm{rpm}$. After specific time interval, UV-Visible spectra were recorded. The pyrene is not soluble in water. Hence, the release of pyrene will lower the intensity of the spectra. ${ }^{4,5}$ Cumulative release of pyrene was determined by the following equation:

$$
\text { Cumulative release }=\frac{\text { cumulative amount of release pyrene }}{\text { amount of loaded pyrene }} \times 100 \%
$$

The relative polarity of the micellar environment where the guest molecule, pyrene is situated was determined by the fluorescence spectroscopy. The $I_{1} / I_{3}$ values of pyrene determines the relative polarity of the micellar environment. The concentrations of copolymers were kept above their CMC values for these experiments. ${ }^{4}$

\section{Loading and Release of 5-Fluorouracil and Doxorubicin at Different pH}

Loading of 5-fluorouracil was performed as follows. The MBC (10 mg) was dissolved in DMF $(1 \mathrm{~mL})$ and then 5-fluorouracil (10 mg) was added into the solution. Next, PBS (pH 7.4, $9 \mathrm{~mL})$ was added into the solution of $\mathrm{MBC}$ for 20 min under vigorous stirring. The stirring was continued for $1 \mathrm{~h}$. The solution was then dialyzed against PBS ( $\mathrm{pH} 7.4,24 \mathrm{~h}$ ). The outside media was changed after $12 \mathrm{~h}$. The loading capacity was estimated by the standard calibration curve using UV-Visible spectrophotometer.

The release of 5-fluorouracil was undertaken as follows. The release experiments were conducted using the dialysis method. The drug-loaded solution was dialysed (MWCO 2000 Da) against the PBS of pH 7.4 at $37{ }^{\circ} \mathrm{C}$. After a specific time interval, inside and the outside media was analysed by the UV-Visible spectrophotometer. The lowering of absorbance values of inside solution was taken, since the absorbance values of outside solution was low due to dilution effect of large volume of PBS (sink condition). The outside solution was changed by 
fresh PBS after each sampling. The cumulative release of the drugs was determined by standard calibration curve. Similarly, the release experiments were conducted at $\mathrm{pH} 5$ by adjusting the solutions $\mathrm{pH}$ (outside and inside the dialysis membrane) by the addition of $\mathrm{HCl}$. Similarly, the loading and release of doxorubicin was performed.

\section{Evaluation of Antimicrobial Activity of the MBCs}

The antibacterial activity of the MBCs was evaluated using a plate-counting method with Bacillus subtilis (B. subtilis) as model Gram-positive bacteria. The cells of B. subtilis were directly taken and grown in $10 \mathrm{~mL}$ of LB media at $37^{\circ} \mathrm{C}$ for $12 \mathrm{~h}$ with shaking at $120 \mathrm{rpm}$. The bacterial cells were then diluted (1:50) in fresh LB medium and cultivated for $\sim 3 \mathrm{~h}$ to reach mid-exponential phase. The bacteria-containing broth was centrifuged at $2700 \mathrm{rpm}$ for $10 \mathrm{~min}$, and after the removal of the supernatant, the cells were washed twice with sterile phosphatebuffered solution (PBS), and re-suspended in PBS at a concentration of $10^{7}$ cells $/ \mathrm{mL}$. The colony-counting test was performed by mixing $200 \mu \mathrm{L}$ of $10^{7} \mathrm{CFU} / \mathrm{mL}$ diluted bacterial suspension with $200 \mu \mathrm{L}$ of sample $(2 \mathrm{mg} / \mathrm{mL}), 1 \mathrm{mg} / \mathrm{mL}$, and $0.5 \mathrm{mg} / \mathrm{mL}$ to make final concentration of $1 \mathrm{mg} / \mathrm{ml}, 0.5 \mathrm{mg} / \mathrm{mL}$, and $0.25 \mathrm{mg} / \mathrm{mL}$ of sample followed by 4 h of incubation at $37{ }^{\circ} \mathrm{C}$ with shaking speed of $120 \mathrm{rpm}$. Then, $10 \mu \mathrm{L}$ of the mixture was plated onto $\mathrm{LB}$ agar plates, and the number of the colonies was counted after $24 \mathrm{~h}$. Plates containing only medium or bacterial suspension were also prepared as controls. The viable cell counts of the bacteria were measured by the surface spread-plate method. The live bacterial counting was done and compared.

\section{Evaluation of Cytocompatibility and Hemocompatibility of the MBCs}

Cell viability of the copolymers samples was determined using HepG2 cells by the MTT assay. HepG2 cells $\left(1 \times 10^{4}\right.$ cells/well $)$ were seeded per well in a 96-well plate and incubated in a $\mathrm{CO}_{2}$ incubator for $24 \mathrm{~h}$ at $37^{\circ} \mathrm{C}$. The MBC solutions $(0.1-1 \mathrm{mg} / \mathrm{ml})$ were added into the well and 
incubated for another $24 \mathrm{~h}$ at $37^{\circ} \mathrm{C}$. Cells seeded in polystyrene tissue culture plates were used as a control. Then media was changed with an equal volume of fresh media and $30 \mu \mathrm{L}$ of 3 (4,5-dimethylthiazol-2-yl)-2,5-diphenyltetrazolium bromide (MTT) solution (5 mg/mL) was introduced. After incubation for another $3 \mathrm{~h}$, the resultant formazan crystals were dissolved in isopropyl alcohol $(100 \mu \mathrm{l})$, and the absorbance intensity were measured by a microplate reader (Bio-RAD 680, USA) at $570 \mathrm{~nm}$. All experiments were performed in triplicate. The relative cell viability was calculated by the following equation.

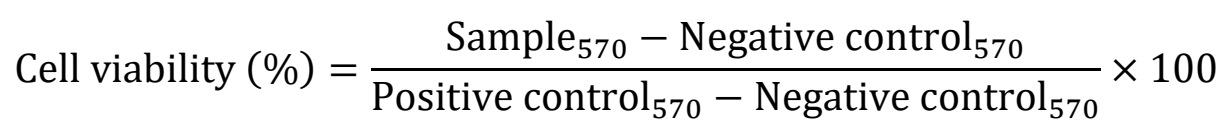

Haemolytic activity was evaluated according to the reported protocol. ${ }^{2}$ The heparinised human blood ( $2 \mathrm{~mL}$ ) was used (blood bank). First, it was centrifuged for $5 \mathrm{~min}$. The deposited cells were collected and then washed thrice with the PBS (pH 7.4). The washed RBC was then appropriately diluted (20 mL PBS). The copolymer solution $(5 \mathrm{mg} / \mathrm{mL}, 100 \mu \mathrm{L})$, was then added to the solution of cells separately $(400 \mu \mathrm{L})$ and allowed to incubate for $3 \mathrm{~h}$ at $37^{\circ} \mathrm{C}$. The PBS $(100 \mu \mathrm{L})$ and Triton $\mathrm{X} 100(10 \mu \mathrm{L}$ of $0.1 \%)$ was used as negative control and positive control respectively. After $3 \mathrm{~h}$ of incubation, tubes were centrifuged at $3000 \mathrm{rpm}$ for $5 \mathrm{~min}$, and the supernatant was taken into the 96 well plates, and then UV-Visible analysis was performed by spectrophotometer (Spectramax plus 384, Molecular Devices, USA) at $540 \mathrm{~nm}$. The extent of haemolysis was calculated by the following formula:

$$
\text { Hemolysis }(\%)=\frac{O D 540_{\text {sample }}-O D 540_{\text {negative control }}}{O D 540_{\text {positive control }}-O D 540_{\text {negative control }}} \times 100
$$

where OD sample, OD negative control, and OD positive control are the absorbance values of the samples, and negative and positive controls respectively. All haemolysis experiments were performed in triplicates. 


\section{Characterization of Prepolymers of the MBC-axy and MBC-fxy Copolymers}

Prepolymers of representative MBC-axy and MBC-fxy copolymers were characterized by ${ }^{1} \mathrm{H}$ NMR spectroscopy (Figure S1 Supporting Information). The signal at $\delta$ values about 3.6 and $4.45 \mathrm{ppm}$ are due to the proton signals of methylene groups of PEG backbone and ester groups respectively. The signal at $\delta$ value $4.6 \mathrm{ppm}$ due to methylene protons of $-\mathrm{C}_{2}-\mathrm{Cl}$ attached to Cl-PEG-Cl was almost disappeared indicating formation of prepolymer by the excess amine through substitution reaction in the presence of base. The signals at $\delta$ values $2.69,1.52$, and 3.62 are from methylene protons of the end groups of the prepolymers (from mono or diamime). The $\mathrm{M}_{\mathrm{n}}$ values of the isolated prepolymers of $\mathrm{MBC}$-axy and $\mathrm{MBC}$-fxy were determined by the following equations $\mathrm{S} 4$ and $\mathrm{S} 5$ repectively:

$$
\begin{gathered}
M_{n}=\frac{I_{3.6} \times 6}{I_{0.9} \times 4} \times 44 \\
M_{n}=\frac{I_{3.6}}{I_{2.53}} \times 44
\end{gathered}
$$

where $\mathrm{I}_{0.9}$ and $\mathrm{I}_{2.53}$ are the intensities of the signals at $\delta$ values about $0.9(6 \mathrm{H}$, methyl) and 2.53 $(4 \mathrm{H}$, methylene) respectively (Figure $\mathrm{S} 1)$ and 44 is the molecular weight of repeat unit of PEG. The $\mathrm{I}_{3.6}$ is the intensity of the protons of PEG backbone. The calculated $\mathrm{M}_{\mathrm{n}}$ values of the PEG in the prepolymers of MBC-axy and MBC-fxy are about $4300 \mathrm{~g} / \mathrm{mol}$, and $4400 \mathrm{~g} / \mathrm{mol}$ respectively. The above calculation was based on exclusive termination of the Cl-PEG-Cl by amines. On the other hand, the calculated $\mathrm{M}_{\mathrm{n}}$ of Cl-PEG-Cl was about $4000 \mathrm{~g} / \mathrm{mol}$ considering the intensity of $\mathrm{I}_{4.6}$ and $\mathrm{I}_{3.6}$. 

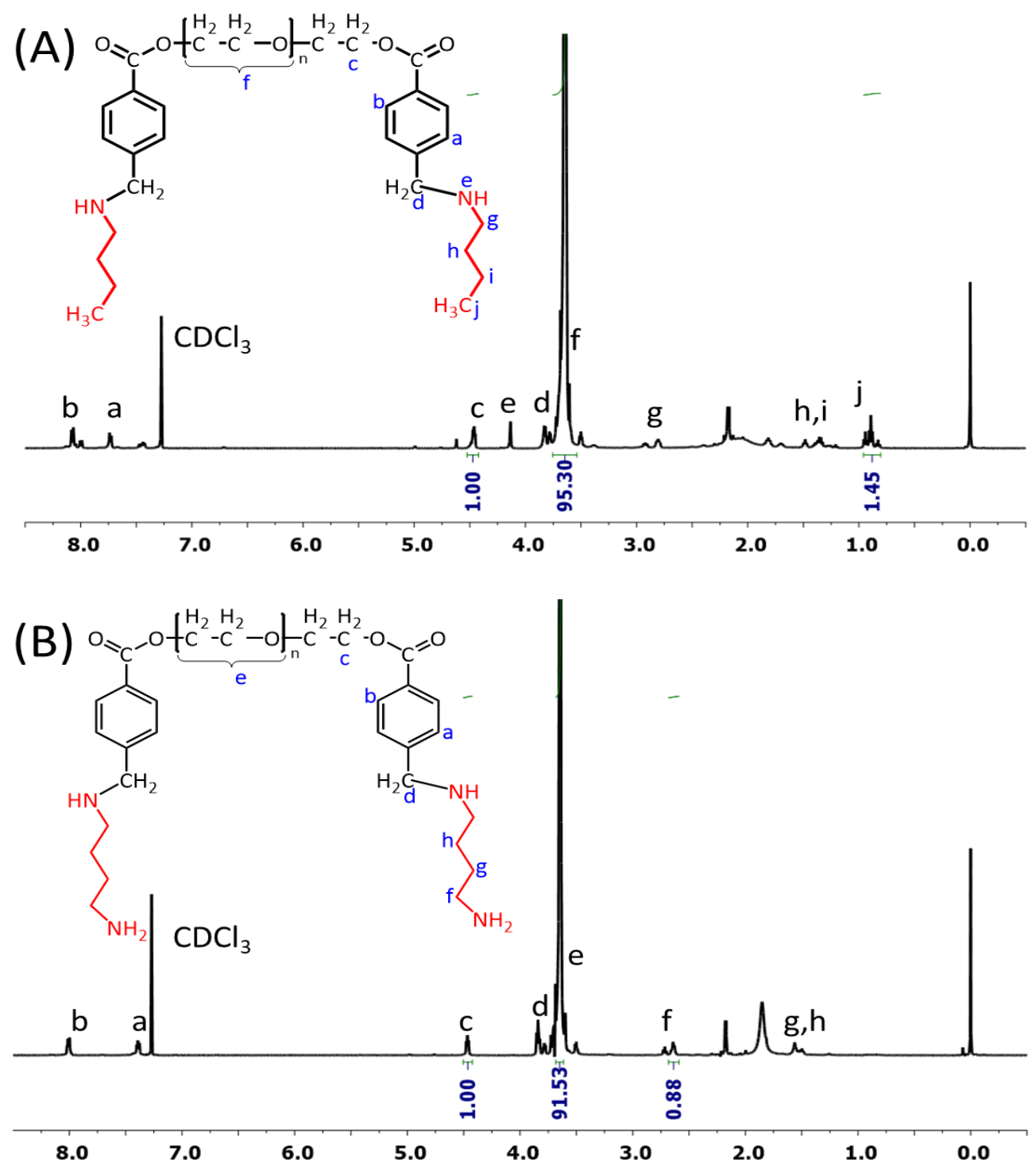

Figure S1. ${ }^{1} \mathrm{H}$ NMR spectra of prepolymers of (A) MBC-axy and (B) MBC-fxy. 


\section{${ }^{1}$ H NMR Spectra of Halide-terminated PEG and PCL, and the Different MBCs}

Figures S2C to S2I shows the NMR spectra of the copolymers. New signal of methylene protons $(2 \mathrm{H})$ of alkyl chain appeared at $\delta$ value $3 \mathrm{ppm}$ for the copolymer. The hydrogen of ester methylene peak appeared at $\delta$ values 4.2 and 4.4 respectively for the ester moieties attached to PCL and PEG chains respectively. A quartet at $\delta=4.01$ and singlet at $\delta=3.6$ appeared due to protons of ester methylene of PCL backbone and protons of PEG backbone respectively. The ratio $\left(\mathrm{I}_{3.6} / \mathrm{I}_{4.01}\right)$ of methylene protons of PEG backbone to PCL backbone was nearly equal to the feed ratio $(\mathrm{mol} / \mathrm{mol})$ of the two polymers used for the synthesis of the copolymers. Since the ${ }^{1} \mathrm{H}$ NMR spectra of purified (purified by precipitation and dialysis) copolymers were taken, the unreacted prepolymers amount is insignificant.

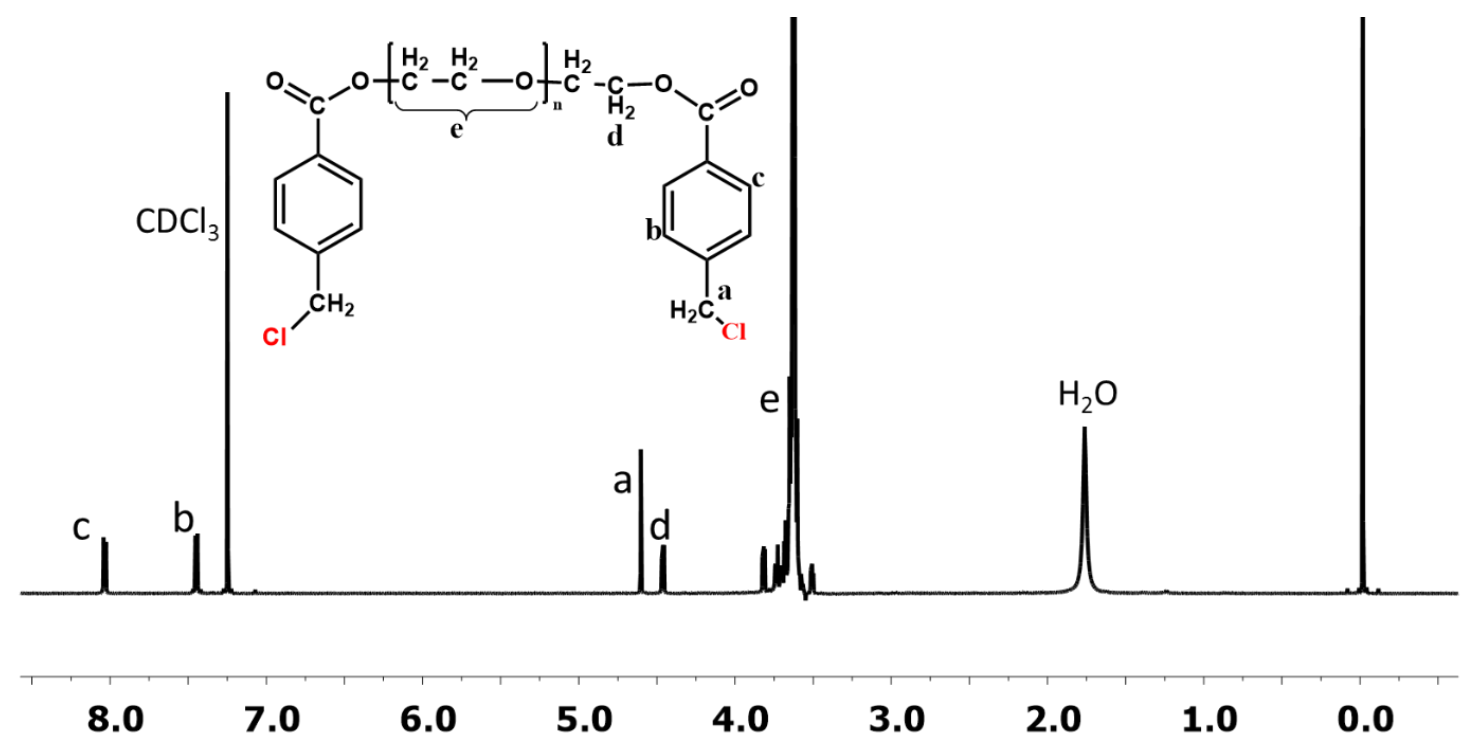

Figure S2A. ${ }^{1} \mathrm{H}$ NMR $\left(600 \mathrm{MHz}, \mathrm{CDCl}_{3}\right)$ spectra of $\mathrm{ClCH}_{2} \mathrm{Ph}-\mathrm{PEG}-\mathrm{Ph}-\mathrm{CH}_{2} \mathrm{Cl}$. 


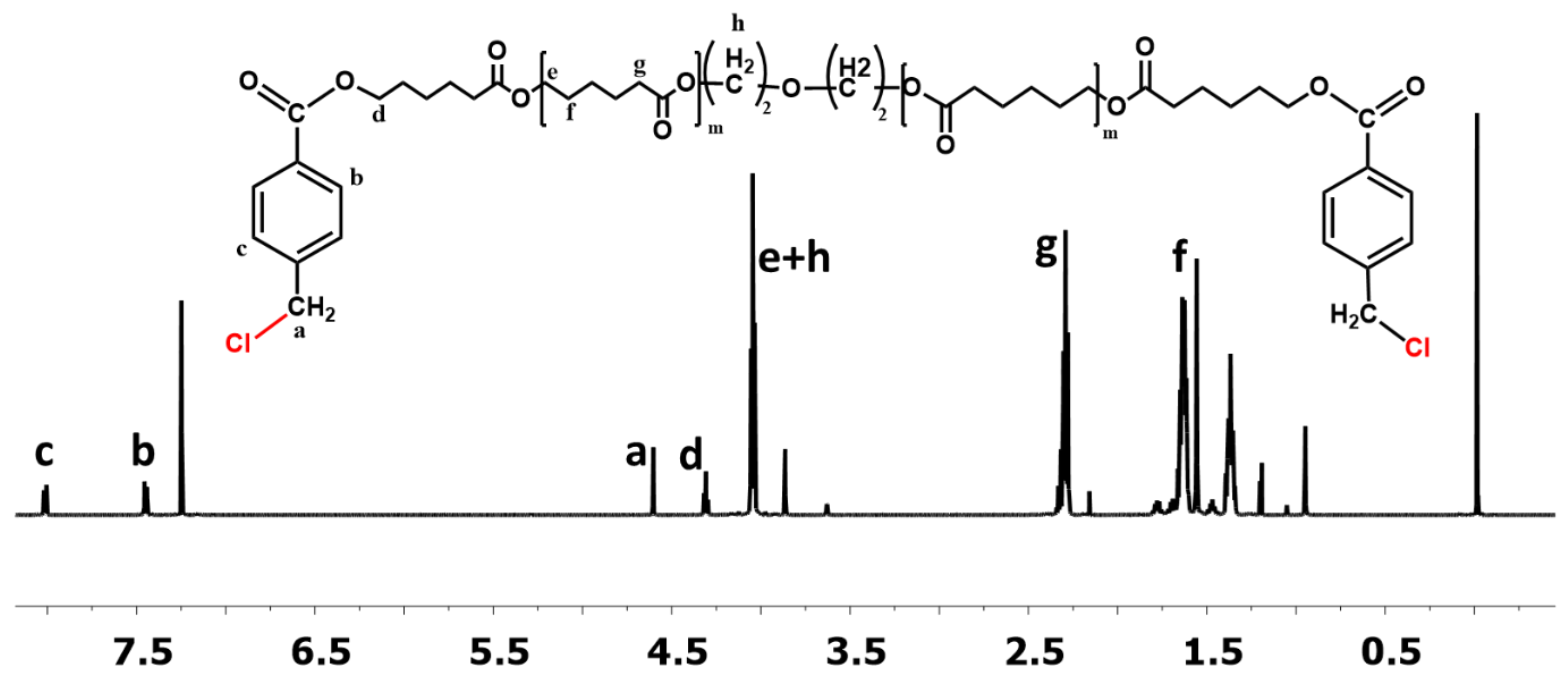

Figure S2B. ${ }^{1} \mathrm{H}$ NMR $\left(200 \mathrm{MHz}, \mathrm{CDCl}_{3}\right)$ spectra of $\mathrm{ClCH}_{2} \mathrm{Ph}-\mathrm{PCL}-\mathrm{Ph}-\mathrm{CH}_{2} \mathrm{Cl}$. 


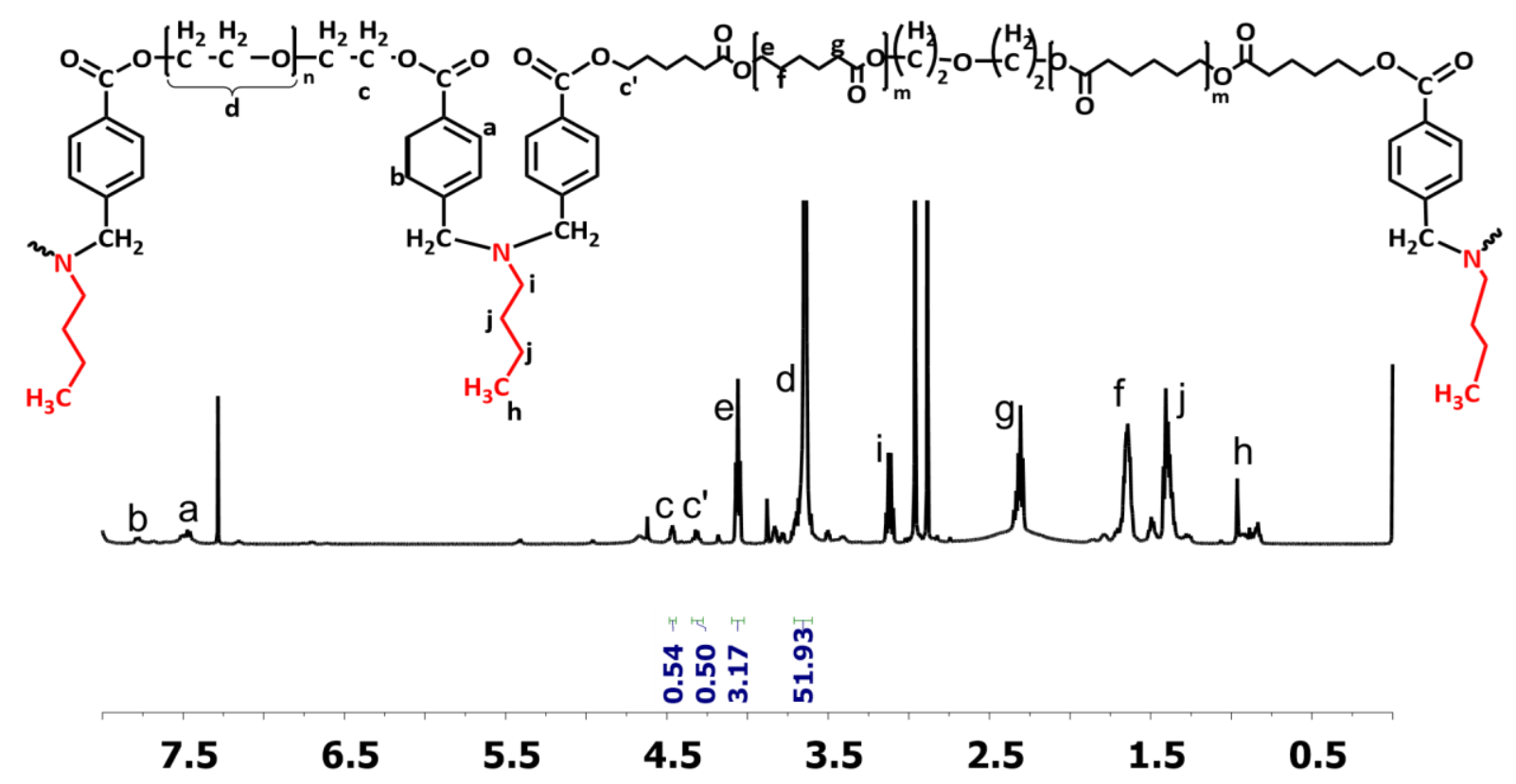

Figure S2C. ${ }^{1} \mathrm{H}$ NMR (200 MHz, $\left.\mathrm{CDCl}_{3}\right)$ spectrum of MBC-axy. 


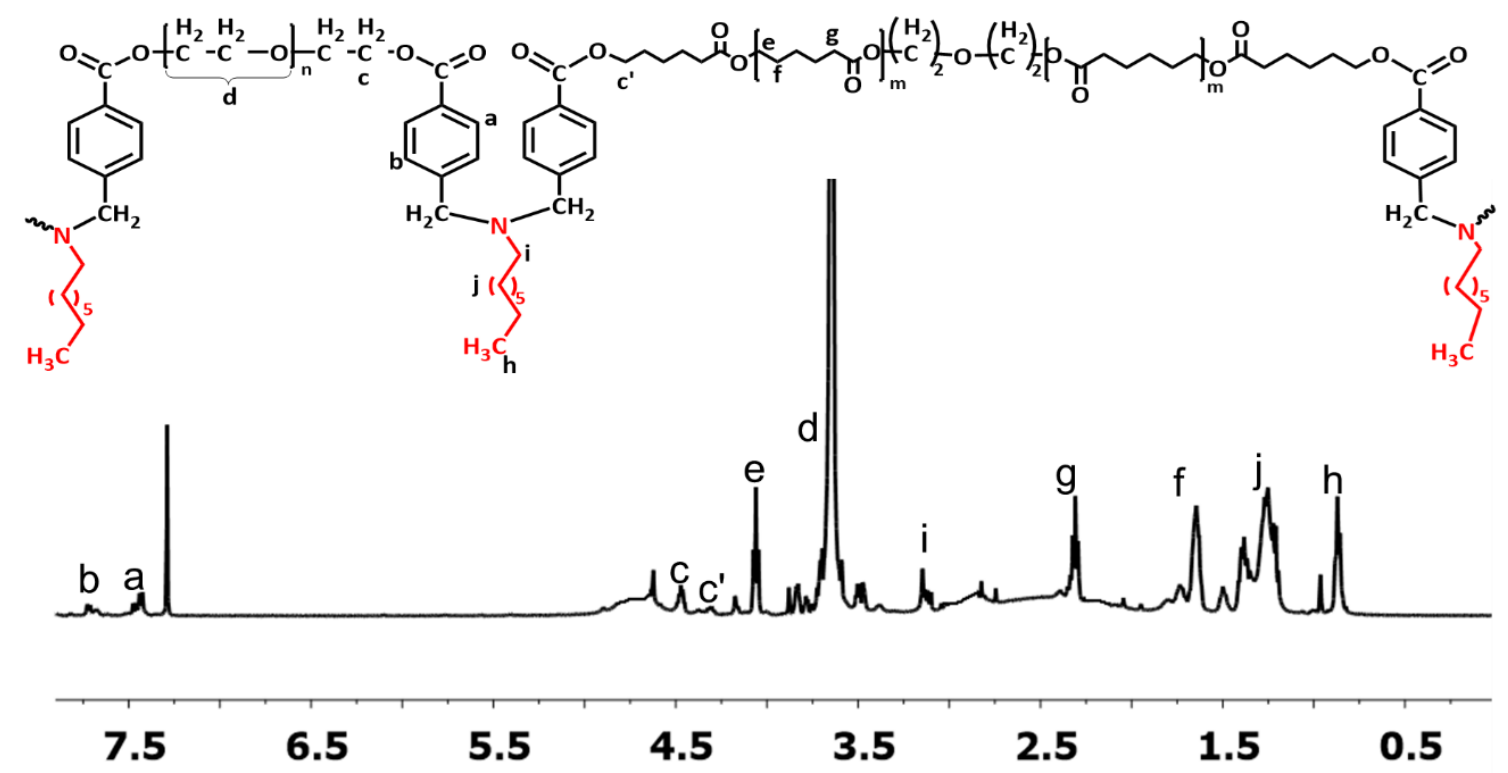

Figure S2D. ${ }^{1} \mathrm{H}$ NMR $\left(200 \mathrm{MHz}, \mathrm{CDCl}_{3}\right)$ spectrum of MBC-bxy. 


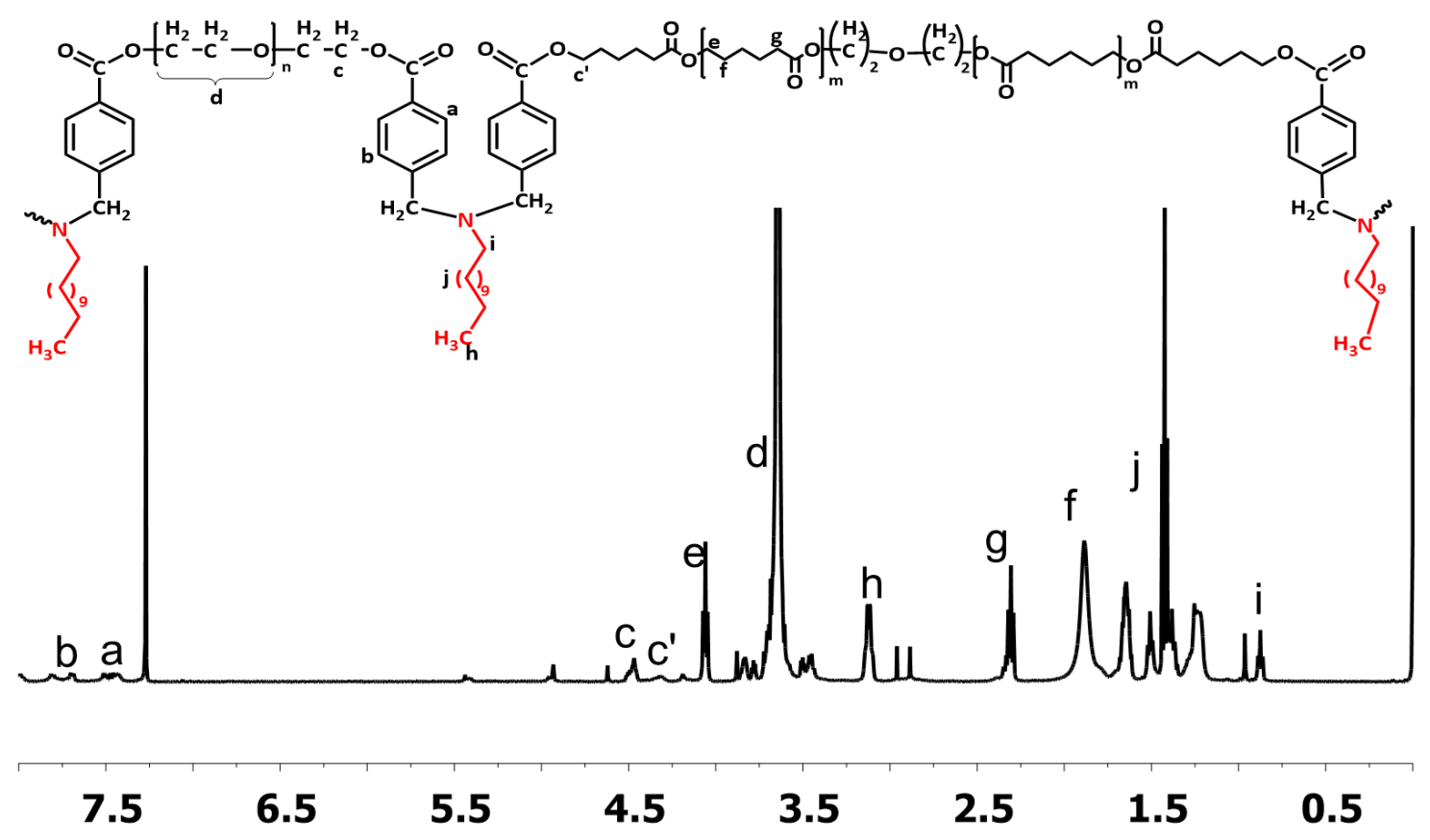

Figure S2E. ${ }^{1} \mathrm{H}$ NMR $\left(200 \mathrm{MHz}, \mathrm{CDCl}_{3}\right)$ spectrum of MBC-cxy. 


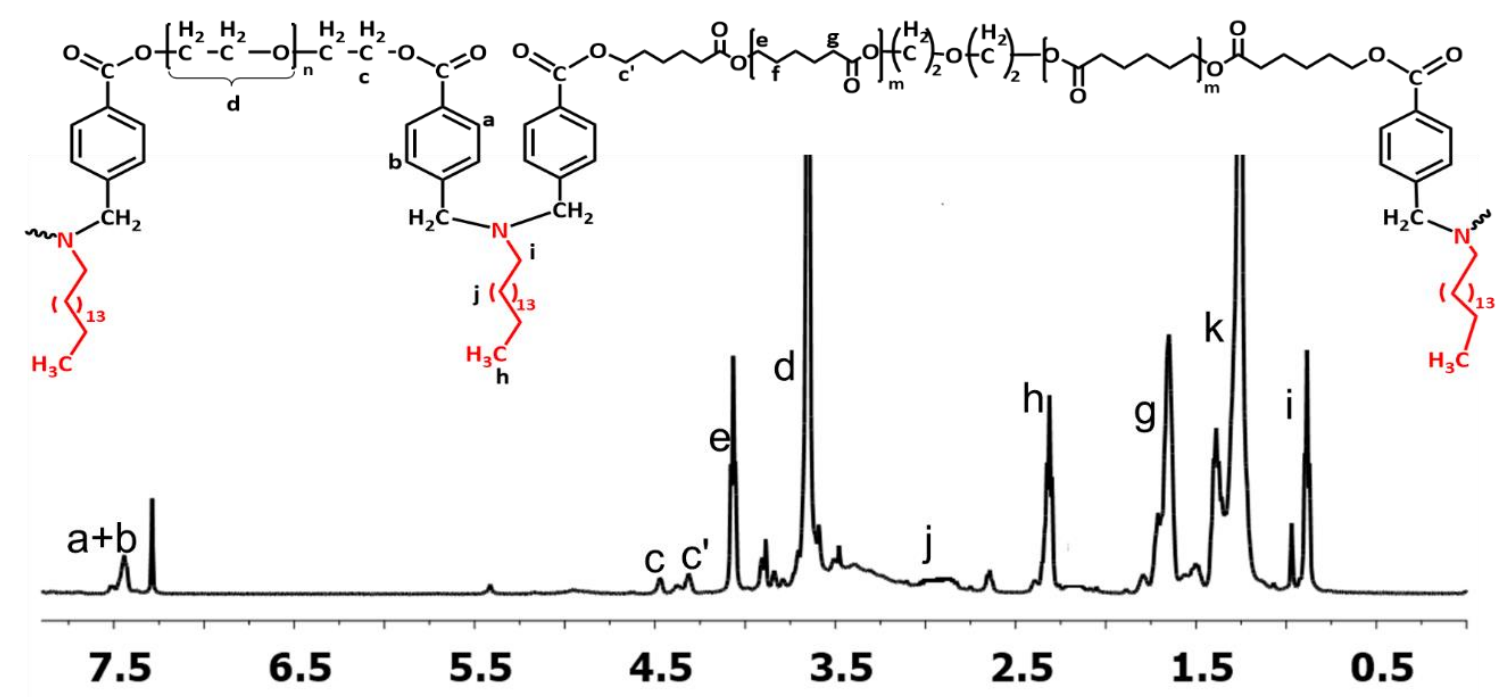

Figure S2F. ${ }^{1} \mathrm{H}$ NMR $\left(200 \mathrm{MHz}, \mathrm{CDCl}_{3}\right)$ spectrum of MBC-dxy. 


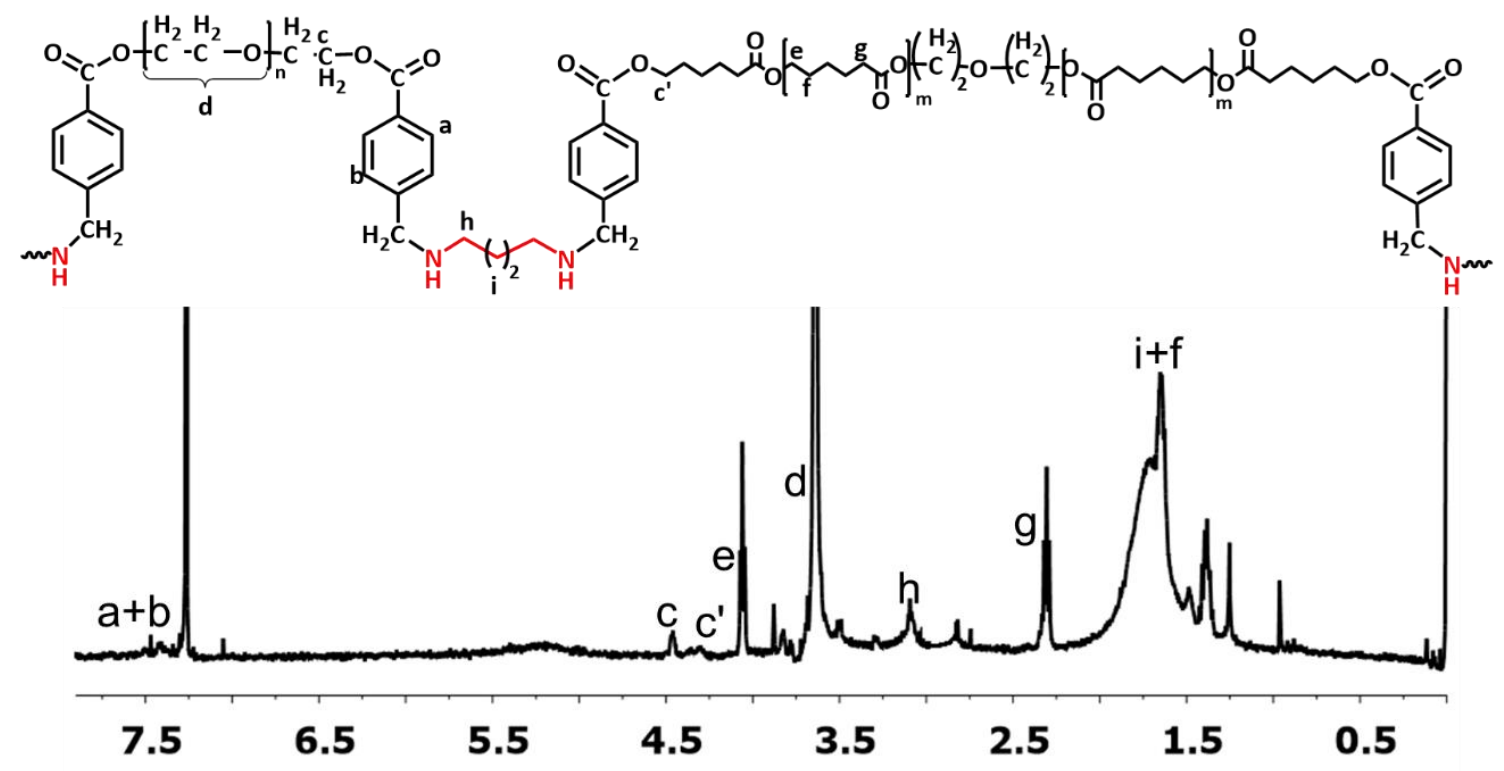

Figure S2G. ${ }^{1} \mathrm{H}$ NMR (200 MHz, $\left.\mathrm{CDCl}_{3}\right)$ spectra of MBC-fxy. 


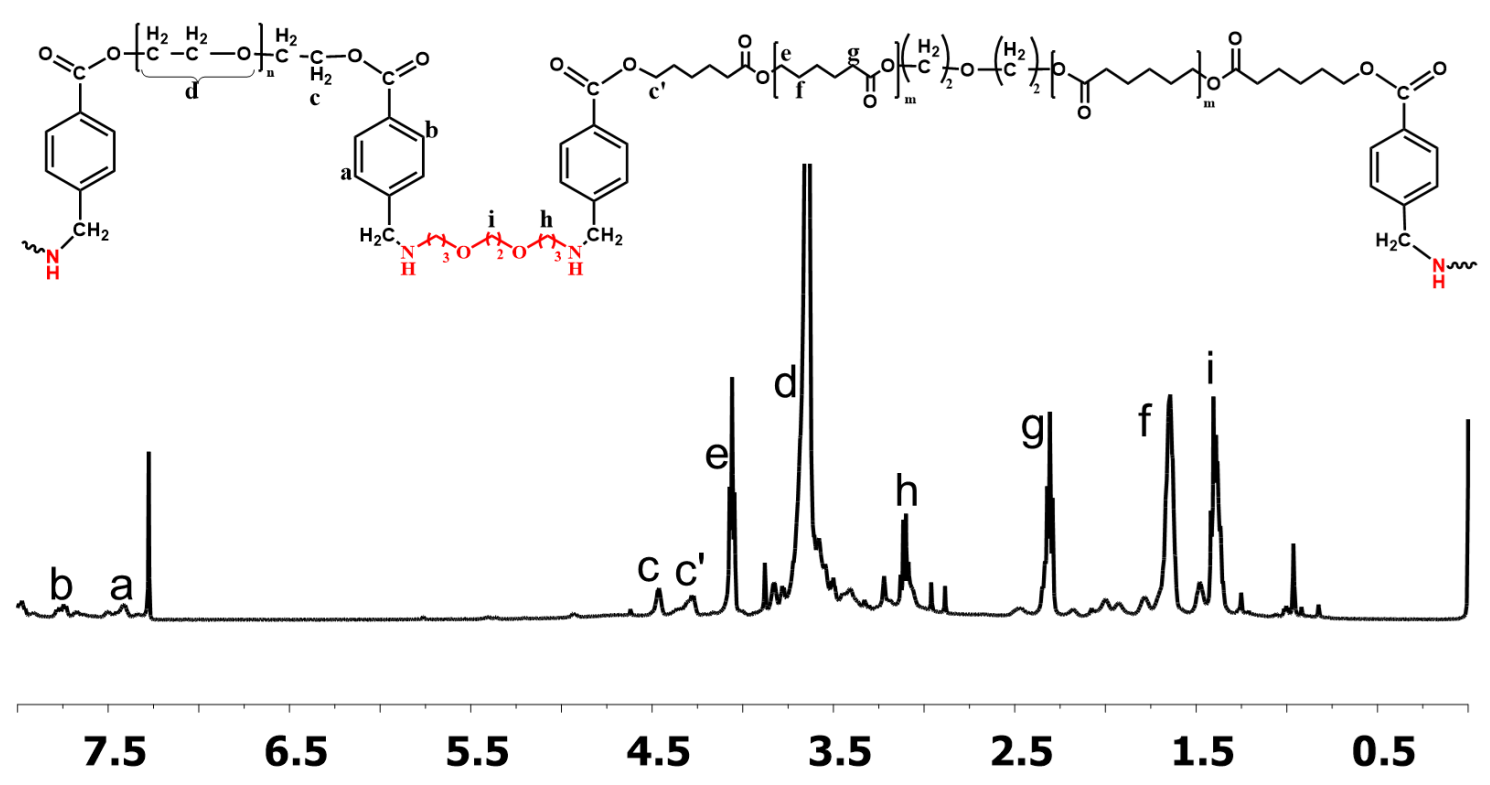

Figure S2H. ${ }^{1} \mathrm{H}$ NMR $\left(200 \mathrm{MHz}, \mathrm{CDCl}_{3}\right)$ spectra of MBC-gxy. 


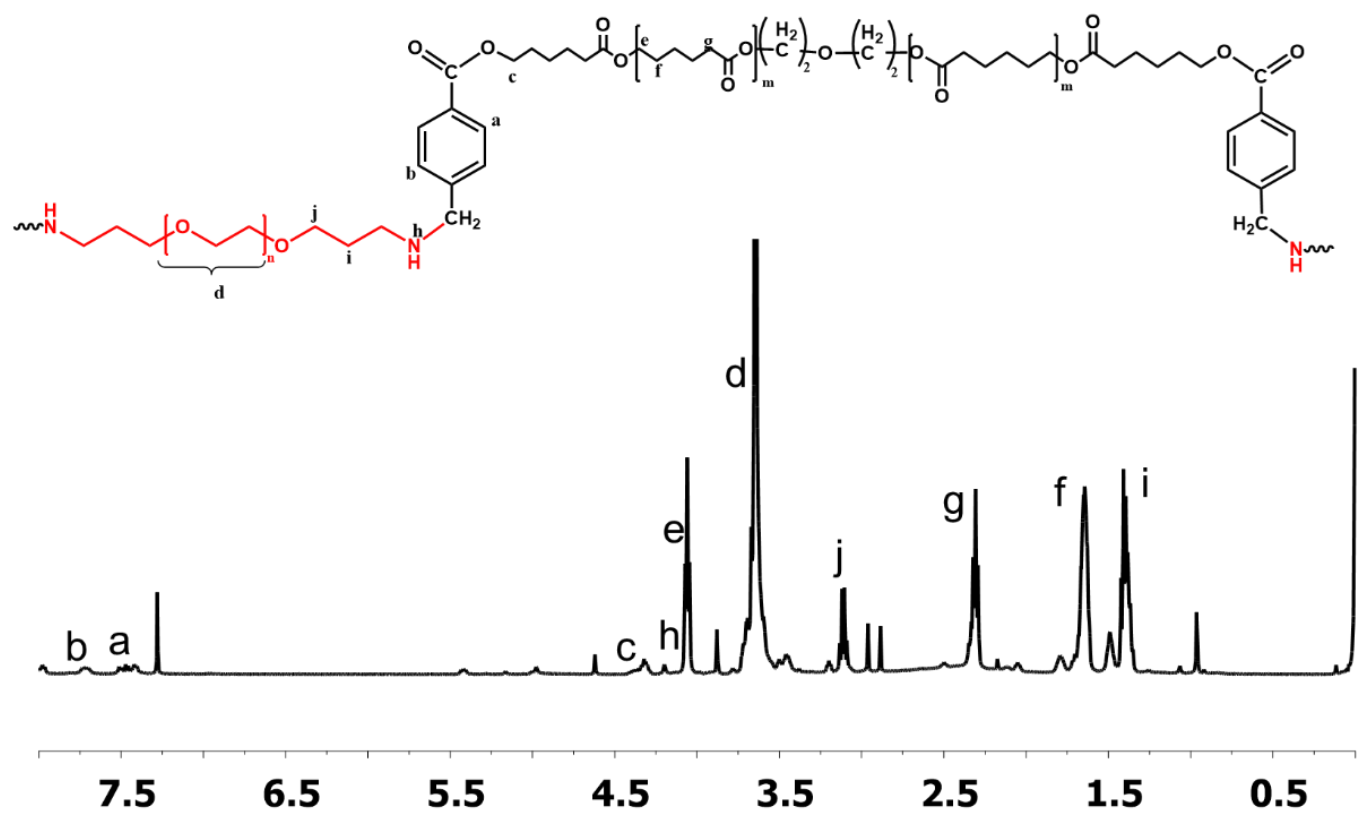

Figure S2I. ${ }^{1} \mathrm{H}$ NMR $\left(200 \mathrm{MHz}, \mathrm{CDCl}_{3}\right)$ spectra of MBC-hy. 
Determination of CMC of the MBCs by Fluorescence Experiments
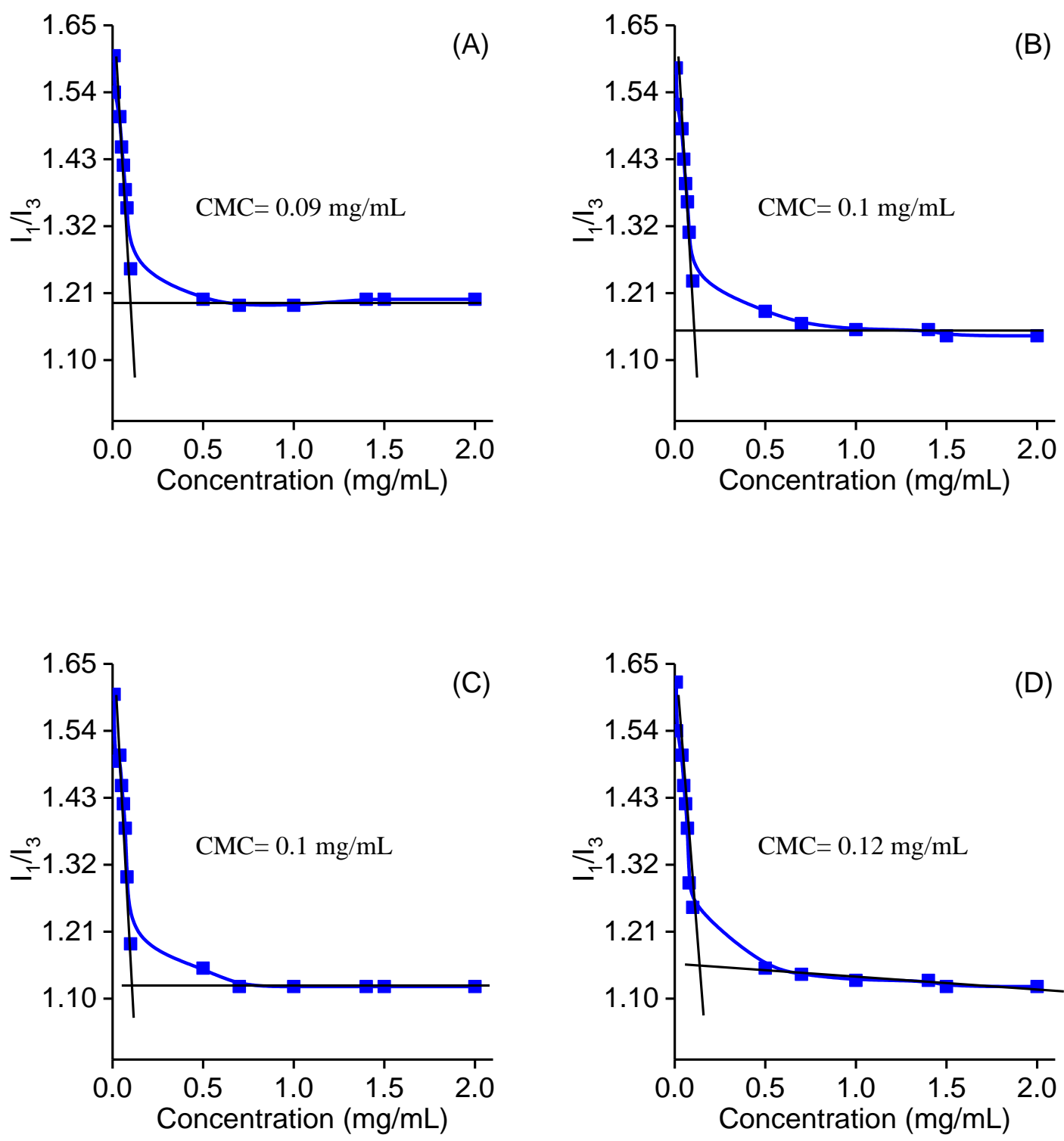

Figure S3. Decrease of $I_{1} / I_{3}$ with the concentration of MBCs. Plots: (A) MBC-axy, (B) MBCbxy, (C) MBC-cxy and (D) MBC-dxy. 

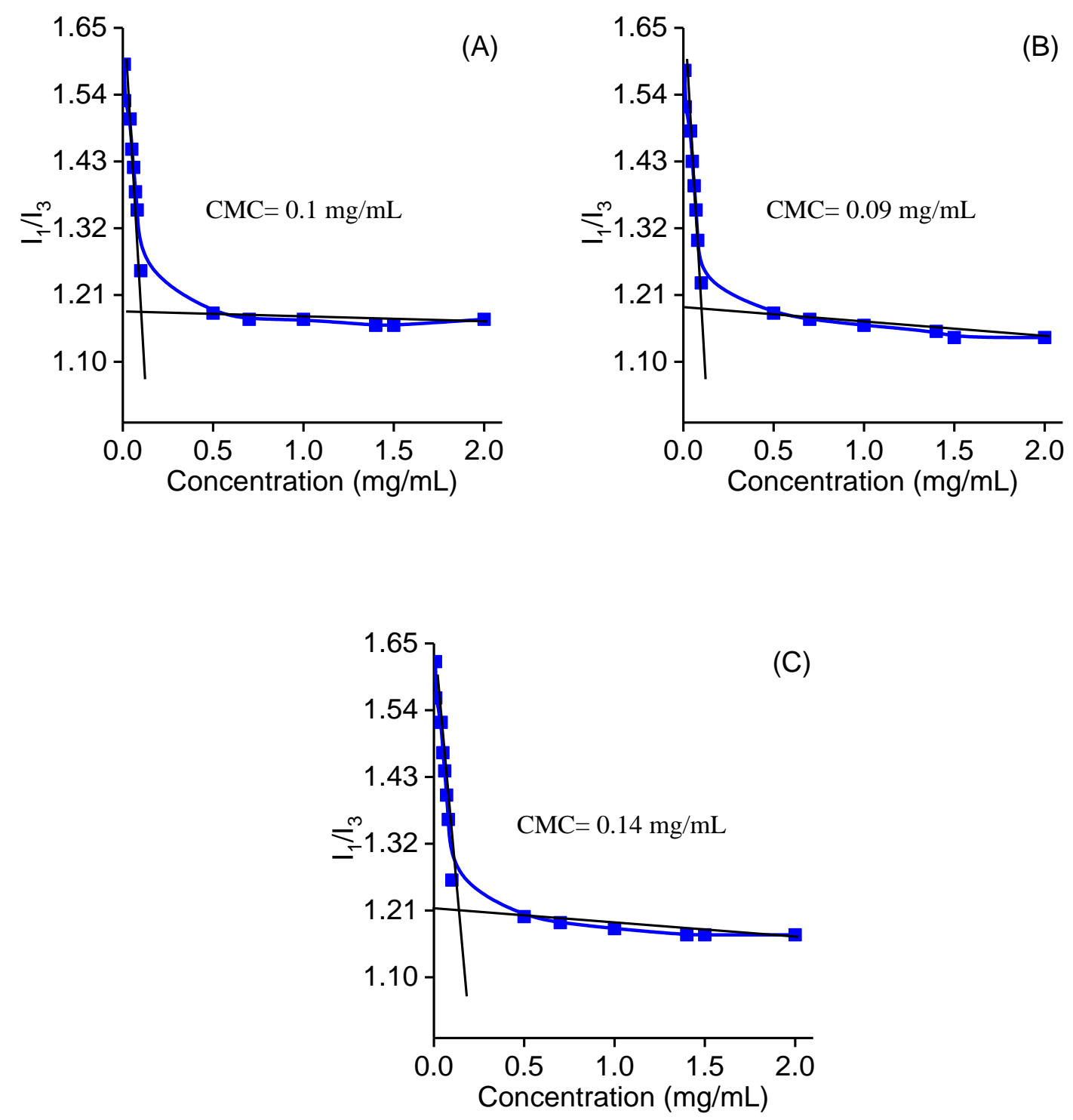

Figure S4. Decrease of $I_{1} / I_{3}$ with the concentration of MBCs. Plots: (A) MBC-fxy, (B) MBCgxy and (C) MBC-hy. 
Effect of Chain Length (C4, and C16) of Primary Amine on the Participation in the Micellar Core Formation

The ${ }^{1} \mathrm{H}$ NMR spectra of MBC-axy and MBC-dxy were recorded in both $\mathrm{CDCl}_{3}$, a good solvent (no micelle formation), and $\mathrm{D}_{2} \mathrm{O}$, a selective solvent for PEG (micelle formation) (Figure S5). The intensity ratio $\left(\mathrm{I}_{0.8} / \mathrm{I}_{3.6}\right)$ of signal due to protons of alkyl side chain to methylene proton of PEG backbone was compared. The ratio decreased in $\mathrm{D}_{2} \mathrm{O}$ for both the copolymers than that in $\mathrm{CDCl}_{3}$. However, MBC-dxy showed about $27 \%$ decrease in the ratio while the MBC-axy showed about $15 \%$ decrease in $\mathrm{D}_{2} \mathrm{O}$. The signal at $0.8 \mathrm{ppm}$ also broadened for MBC-dxy. This indicates greater degree of participation of $\mathrm{C} 16$ in the micellar core formation with PCL chains. The PCL chains of both the MBCs formed core of the micelles as the ${ }^{1} \mathrm{H}$ NMR signal at about $4 \mathrm{ppm}$ for the methylene proton of PCL backbone reduced significantly when the NMR was performed in $\mathrm{D}_{2} \mathrm{O}$.

(A)

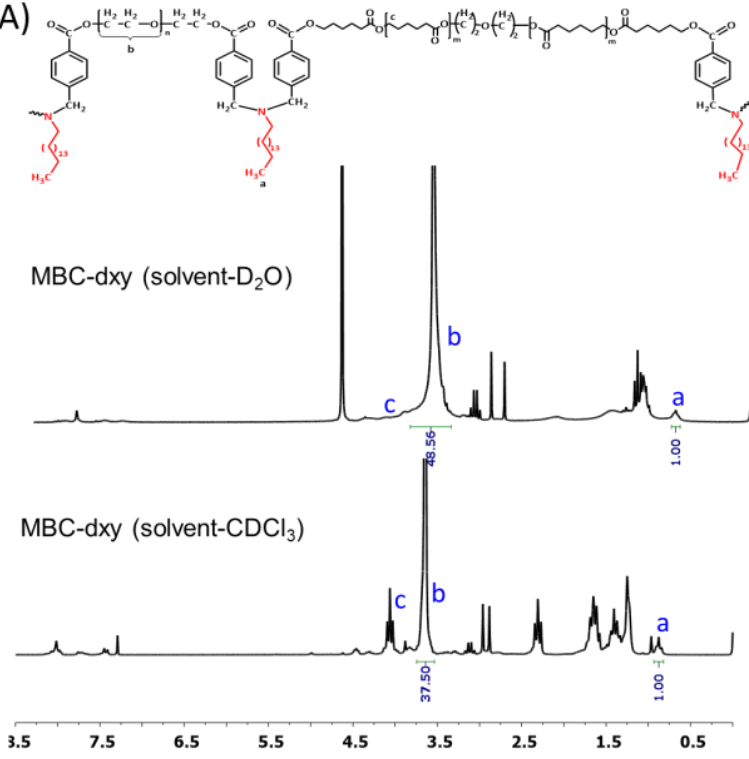

(B)

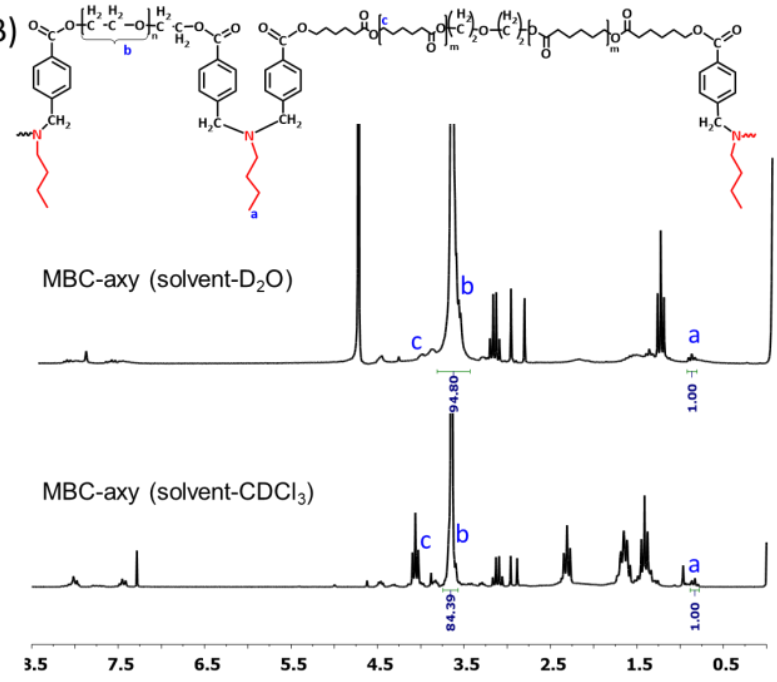

Figure S5. ${ }^{1} \mathrm{H}$ NMR $(200 \mathrm{MHz})$ spectra of (A) MBC-dxy, and (B) MBC-axy in $\mathrm{D}_{2} \mathrm{O}$ and $\mathrm{CDCl}_{3}$ 


\section{Solubility of Pyrene in PCL and Hexadecane}

Pyrene $(2 \mathrm{mg})$ was solubilized in DCM $(1 \mathrm{~mL})$. Then PCL $(2 \mathrm{~g})$ was added in the DCM solution. The admixture was stirred for $1 \mathrm{~h}$ and then sonicated for $2 \mathrm{~min}$. Next, the DCM was evaporated under reduced pressure by a rotary evaporator. The UV-Visible spectrum of the PCL containing pyrene was then recorded. The Soluble pyrene shows intense UV-Visible spectrum (spectrum a, Figure S6A).

Similarly, UV-Visible spectrum of pyrene solubilized in hexadecane $(2 \mathrm{~g})$ was recorded (spectrum b, Figure S6A). The initial amount of pyrene used in these experiments was in excess than that of its solubility in PCL and hexadecane. Thus, some pyrene remained precipitated after complete evaporation of DCM. The amount of precipitated pyrene was higher in hexadecane than that of PCL as observed visually. Higher absorbance intensity of pyrene in PCL indicates its higher solubility than that of hexadecane. However, the absorbance coefficient of pyrene in the PCL and hexadecane may be different. Thus, to correlate spectral intensity, $75 \%$ toluene (v/v) was added in both PCL+pyrene, and hexadecane+pyrene solutions to keep the dielectric property of the two solution similar. For this purpose, the insoluble pyrene was first, remove, and then diluted with toluene. Spectra in Figure S6B shows that the toluene diluted PCL+pyrene showed intense UV bands than that of toluene diluted hexadecane+pyrene. This experiment indicates better solubility of pyrene in PCL than that of hexadecane.
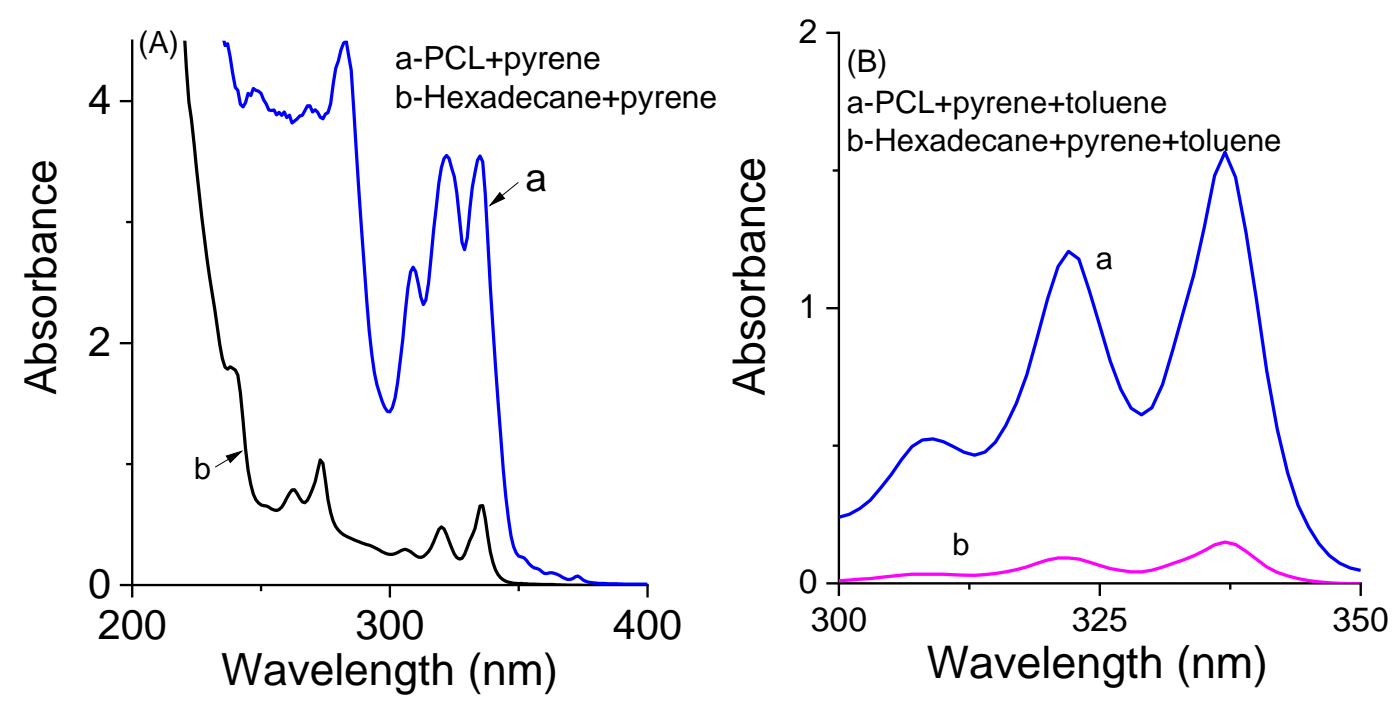

Figure S6. (A) UV-Visible spectra of pyrene solubilized in liquid PCL, and hexadecane. (B) Spectra of pyrene solubilized in liquid PCL, and hexadecane and then equally diluted with toluene. 


\section{Release of Pyrene from the Self-assemblies of MBCs}
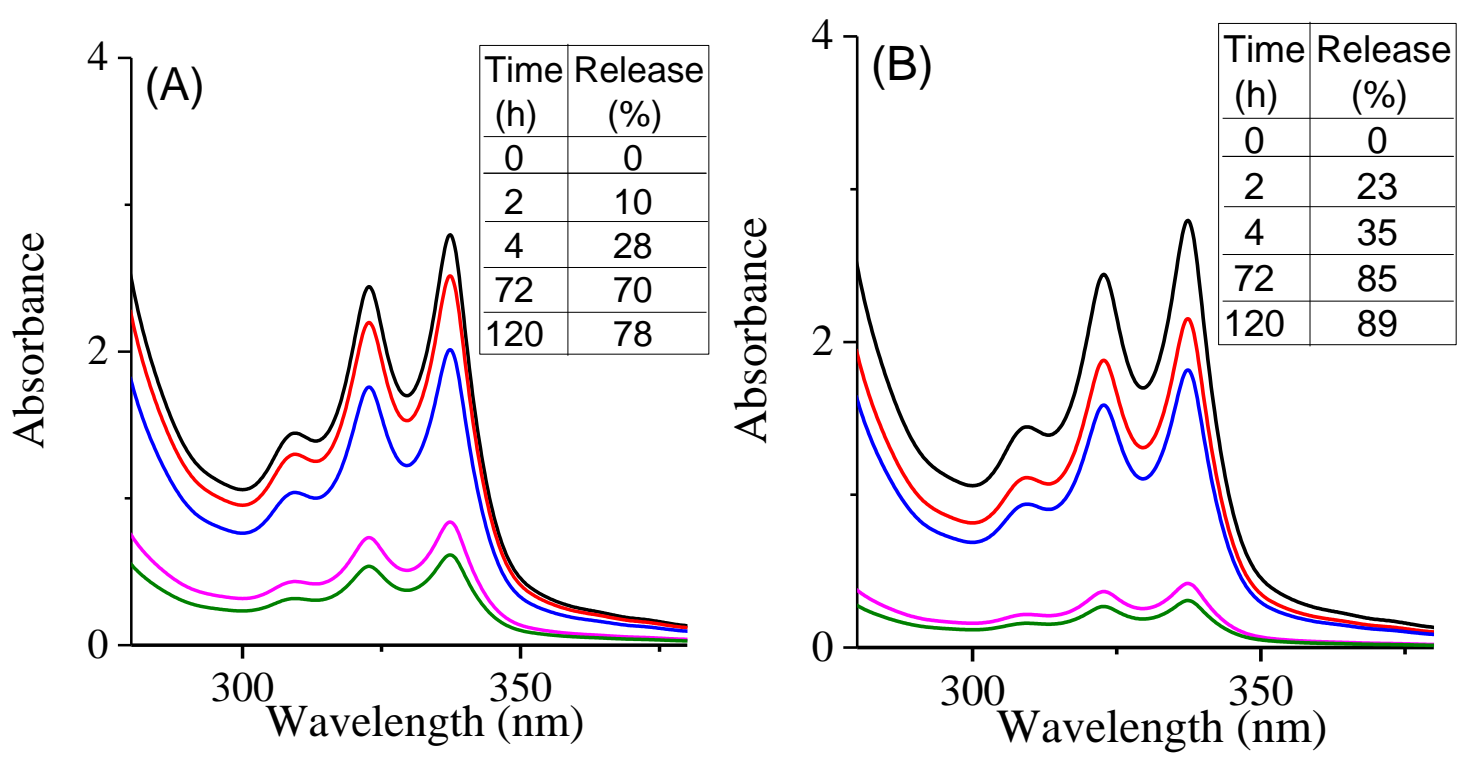

Figure S7A. Change of UV-Visible spectral intensity of pyrene with time after incubation of pyrene encapsulated in the aqueous solution of MBC-bxy at (A) $\mathrm{pH} 7.4$, and $\mathrm{pH} 5$ (B) respectively at $37^{\circ} \mathrm{C}$. 

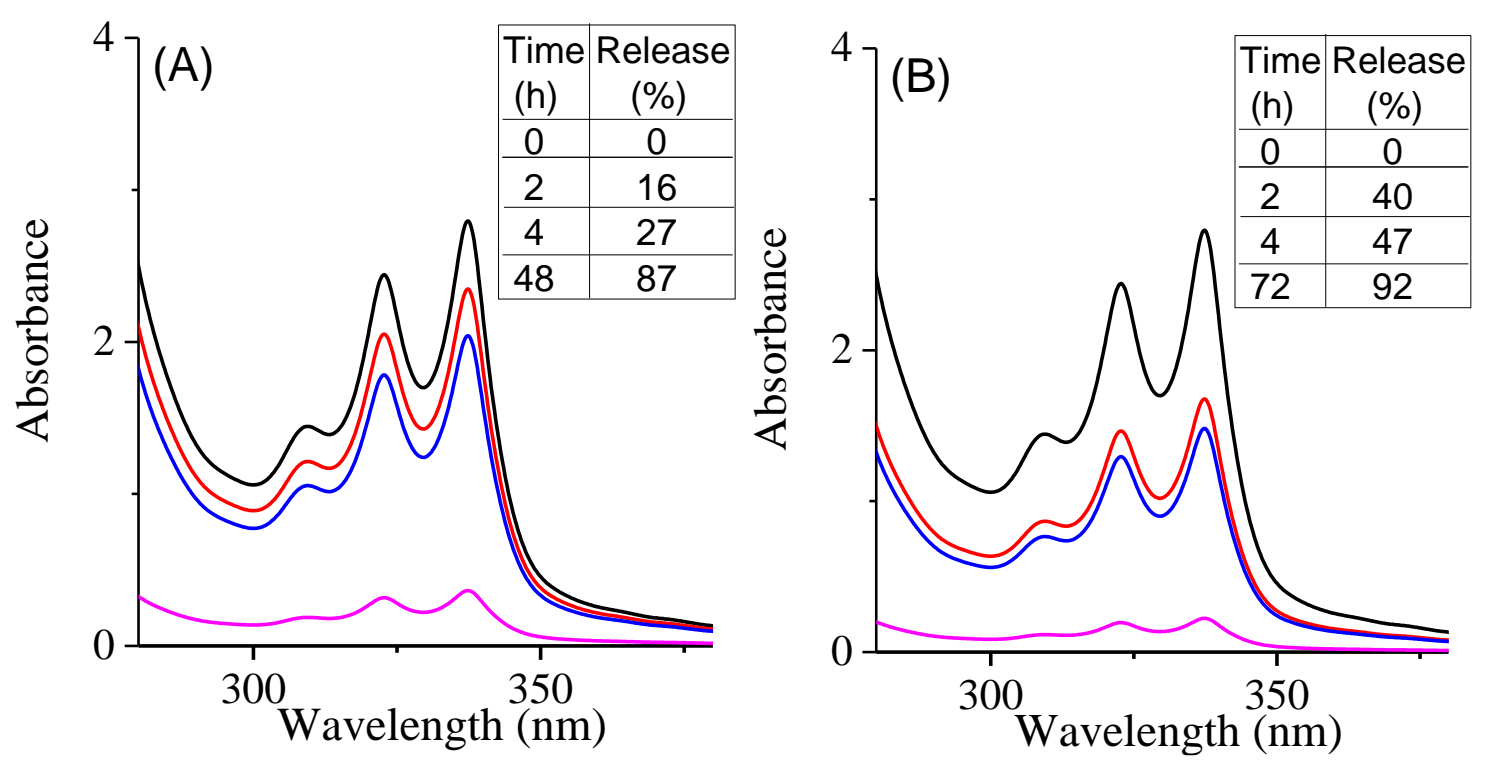

Figure S7B. Change of UV-Visible spectral intensity of pyrene with time after incubation of

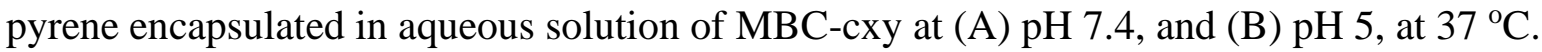



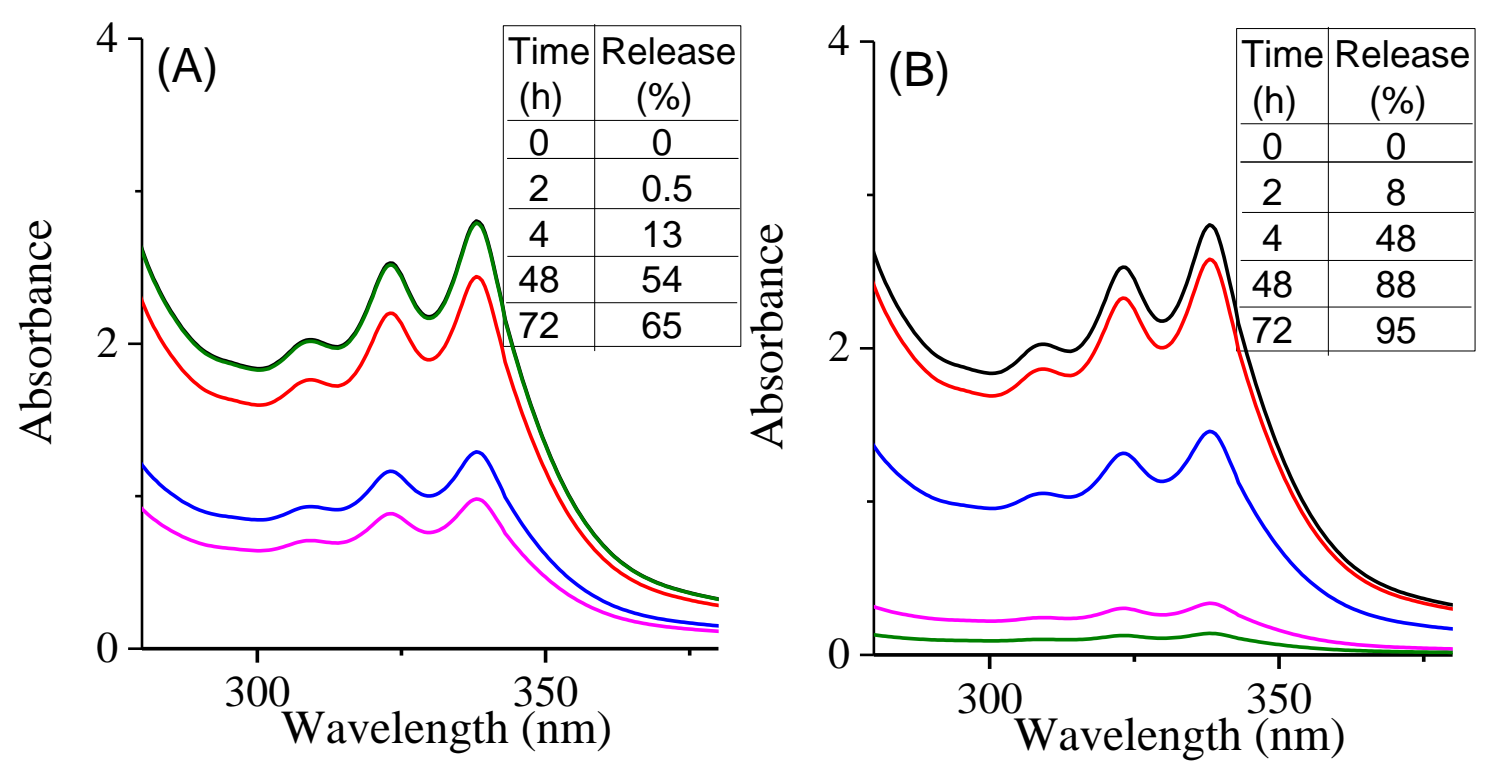

Figure S7C. Change of UV-Visible spectral intensity of pyrene with time after incubation of pyrene encapsulated in aqueous solution of MBC-dxy at (A) pH 7.4, and (B) $\mathrm{pH} 5$ at $37^{\circ} \mathrm{C}$. 

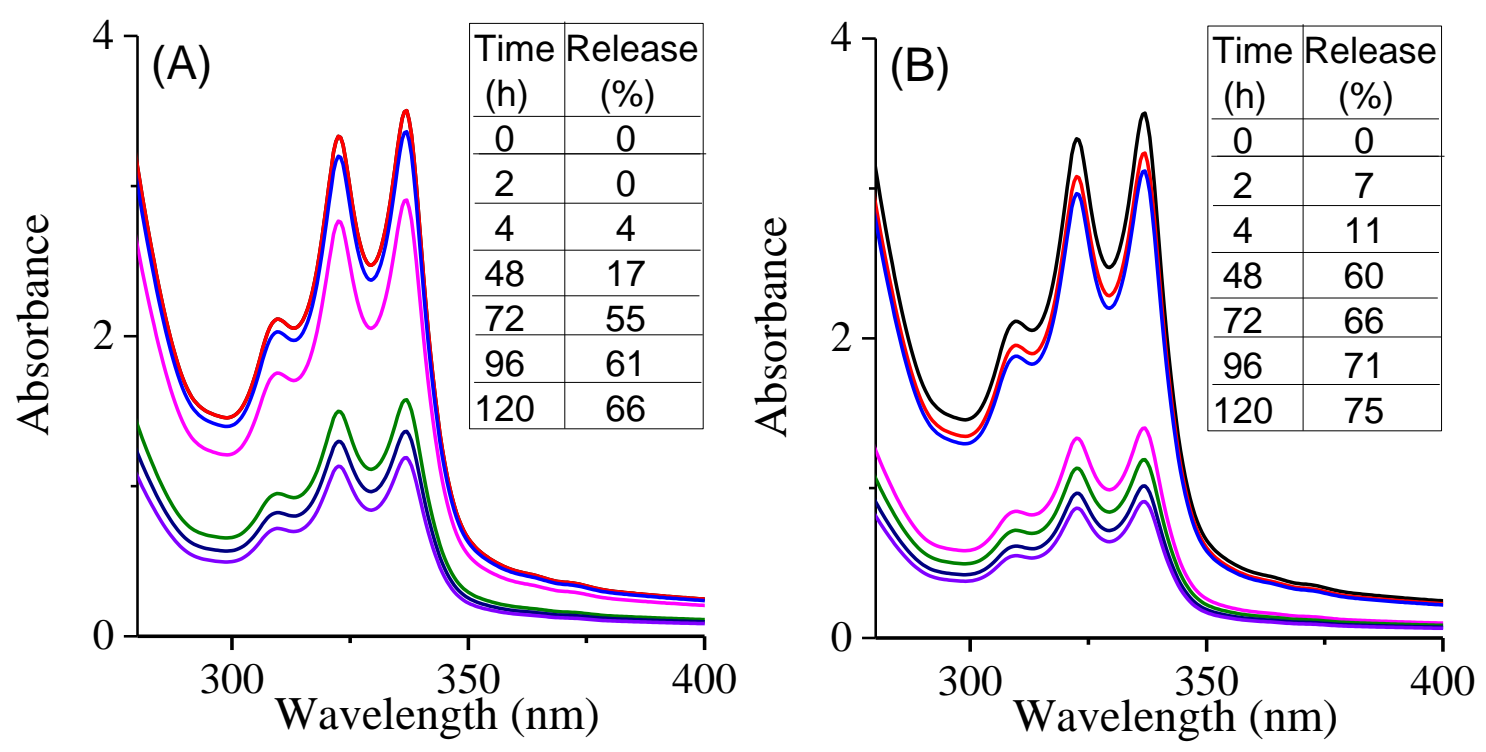

Figure S7D. Change of UV-Visible spectral intensity of pyrene with time after incubation of pyrene encapsulated in aqueous solution of MBC-gxy at (A) $\mathrm{pH} 7.4$, and (B) $\mathrm{pH} 5$ at $37^{\circ} \mathrm{C}$. 

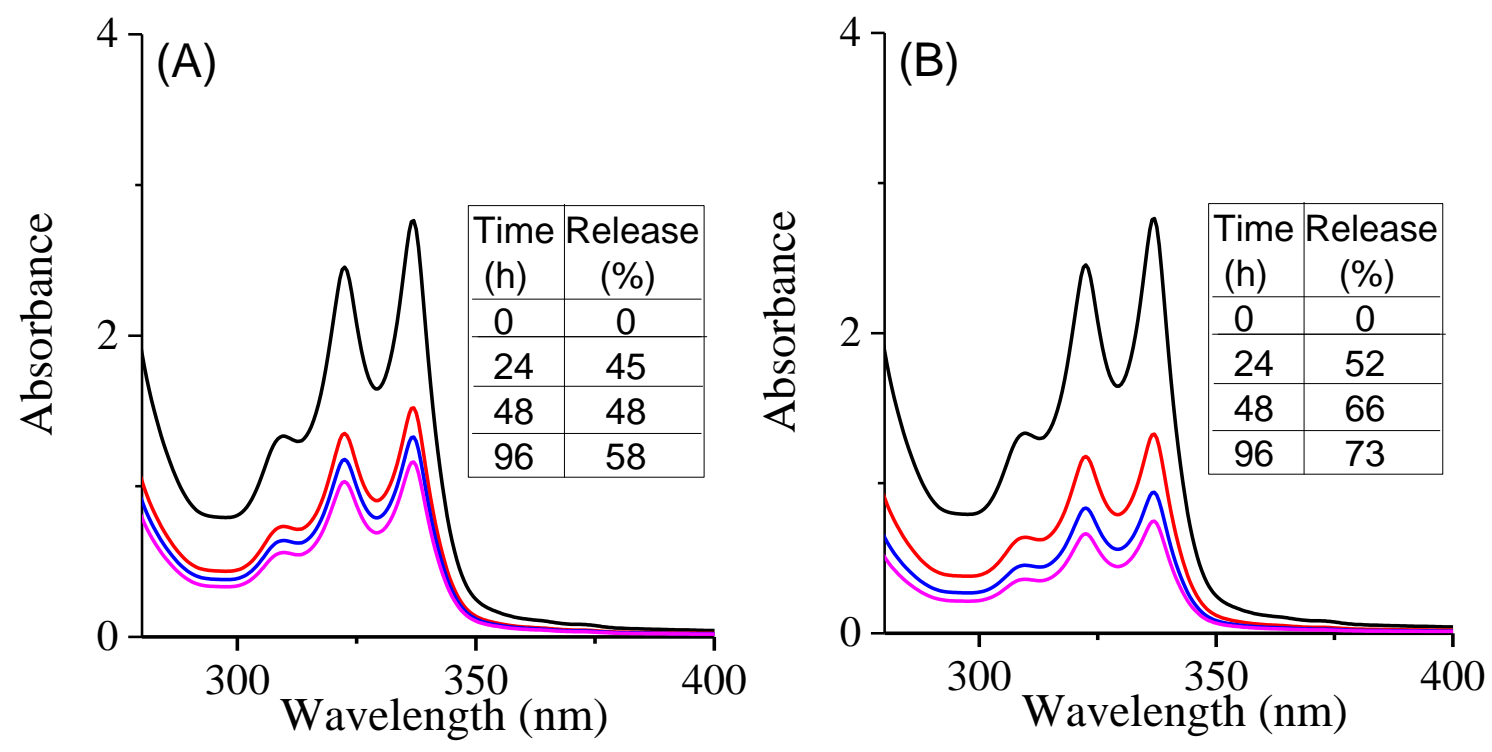

Figure S7E. Change of UV-Visible spectral intensity of pyrene with time after incubation of pyrene encapsulated in aqueous solution of MBC-hy at (A) $\mathrm{pH} 7.4$, and (B) $\mathrm{pH} 5$ at $37^{\circ} \mathrm{C}$. 


\section{Monitoring Degradation of MBCs by GPC, ${ }^{1} \mathbf{H}$ NMR Spectroscopy, and DLS Measurement}

The self-assembly of the MBCs were subjected to the incubation at $\mathrm{pH} 7.4$ and 5 separately for 5 days. After the incubation, the masses of the copolymers were recovered by lyophilisation. The GPC experiments were conducted with the masses obtained after incubation of the MBCs. The GPC traces of the MBCs showed the degradation after incubation at $\mathrm{pH} 5$ and $\mathrm{pH} 7.4$ (Figures S8).

${ }^{1} \mathrm{H}$ NMR spectra of the mass obtained after incubation of representative MBC-fxy after incubation at $\mathrm{pH} 5$ and $\mathrm{pH} 7.4$ for 5 days at $37{ }^{\circ} \mathrm{C}$ indicated presence of both PCL and PEG with all the characteristic proton signals of the copolymers (Figure S9). However, the intensity ratio of methylene protons of ester linkages ( $\delta$ values 4.3 and $4.5 \mathrm{ppm})$ to methylene proton of PEG backbone (3.6 ppm) decreased by $14 \%$, and $30 \%$ after 5 days of incubation at $\mathrm{pH} 7.4$ and pH 5 respectively. This indicates hydrolysis of ester moieties presence in between the blocks. The degradation of ester linkages at $\mathrm{pH} 5$ lowers the $\mathrm{M}_{\mathrm{n}}$ of the MBC. The existence of signals of PEG, PCL and the ester linkages of individual blocks indicates partial degradation. Schematic representation shows the partial hydrolytic degradation of the esters groups (Figure S9, inset). Furthermore, DLS experiments were conducted after incubation of the MBCs at $\mathrm{pH}$

7.4 and 5 for 5 days (Figure S10). The DLS curves show degradation of the MBCs and formation of two differently populated self-assembly structure (particles). All these experiments reveal hydrolytic degradation of the ester linkages of PEG and PCL blocks. 

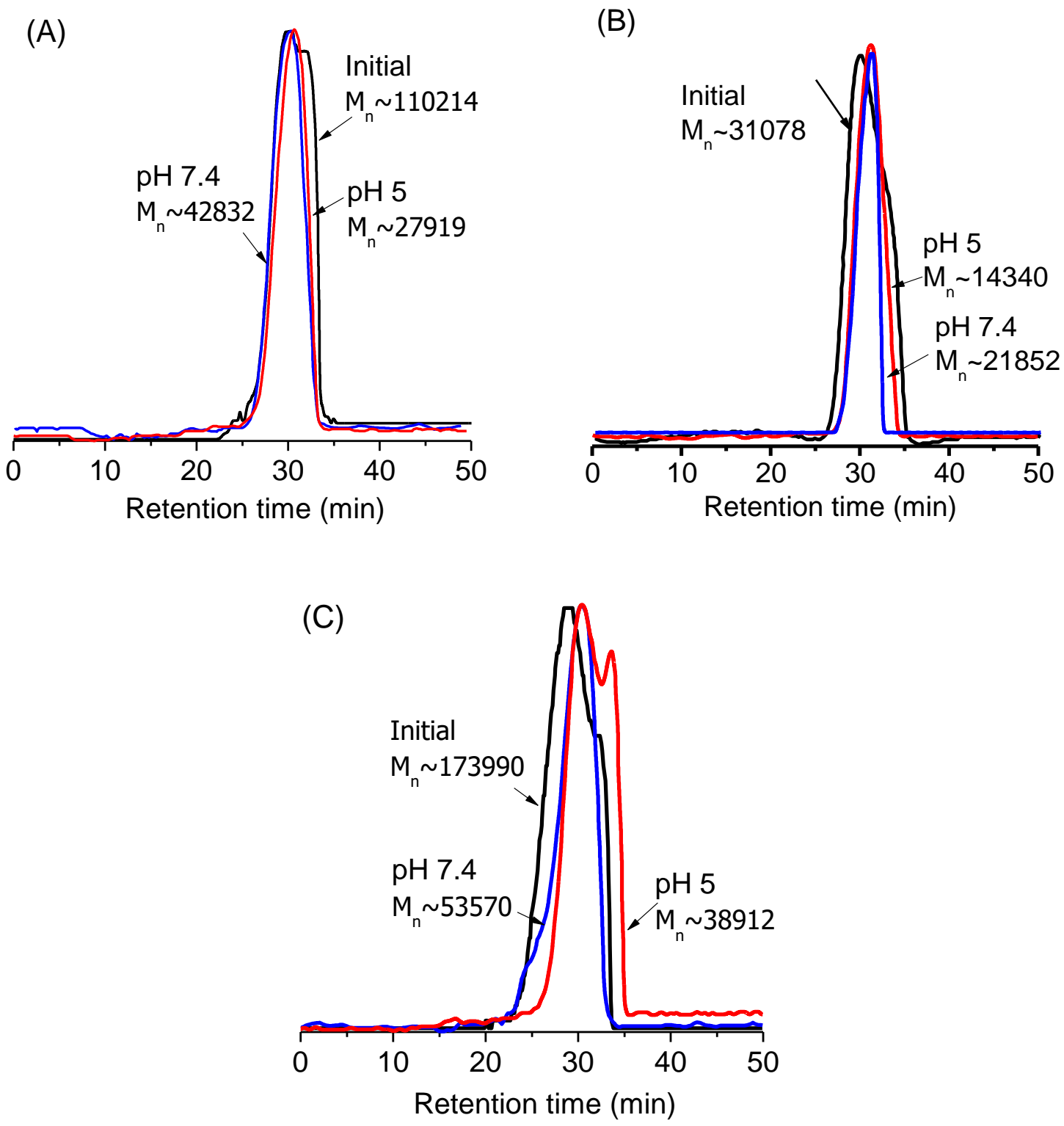

Figure S8. GPC traces of (A) MBC-axy, (B) MBC-cxy and (C) MBC-fxy copolymers recoded before and after incubation at $\mathrm{pH} 7.4$ and $\mathrm{pH} 5$ for 5 days at $37{ }^{\circ} \mathrm{C}$. 


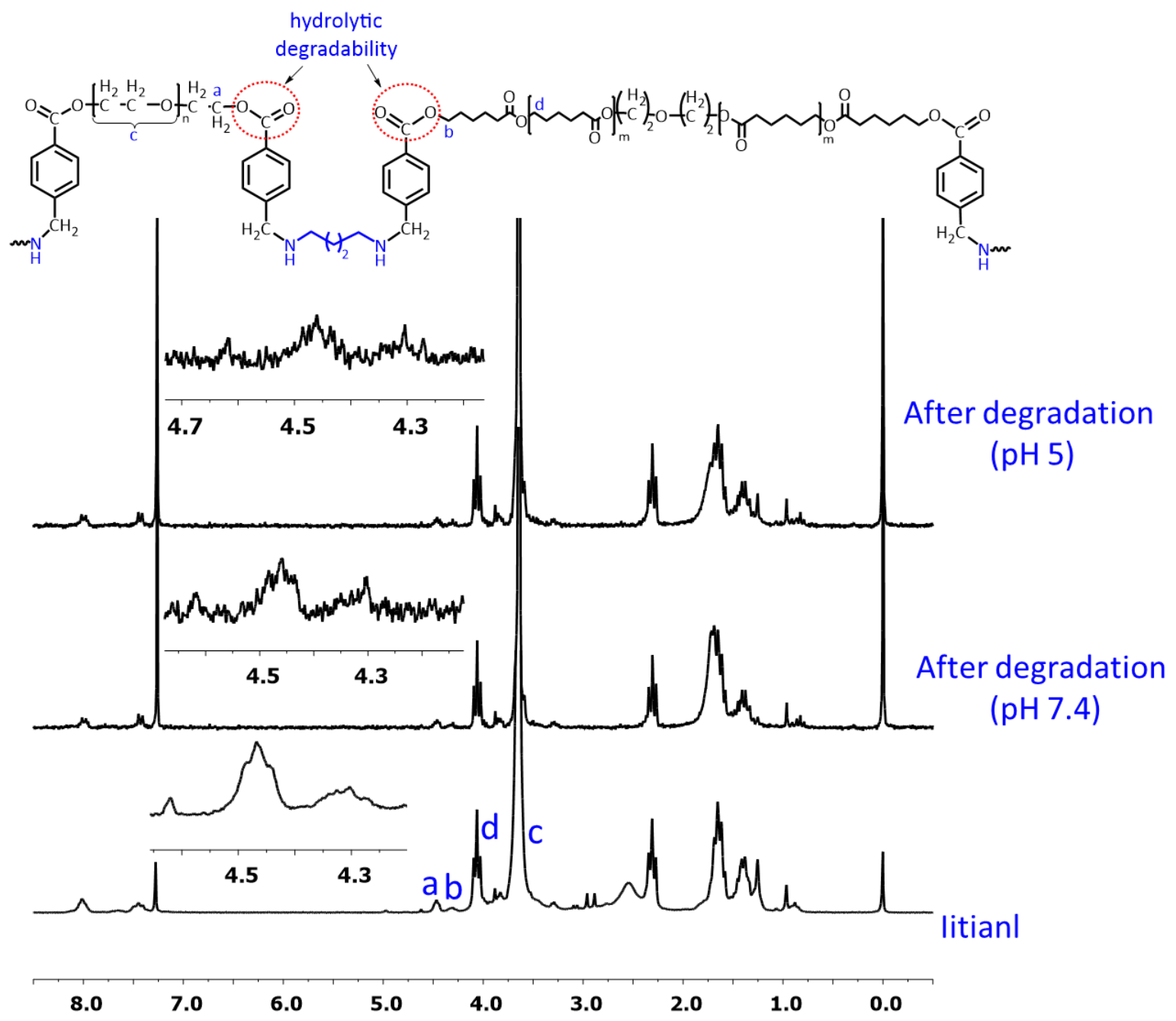

Figure S9. ${ }^{1} \mathrm{H}$ NMR spectrum of mass of MBC-fxy before and after subjected to treatment with aqueous buffer (pH 7.4) and acidic water of $\mathrm{pH} 5$ at $37{ }^{\circ} \mathrm{C}$ for 5 days. 

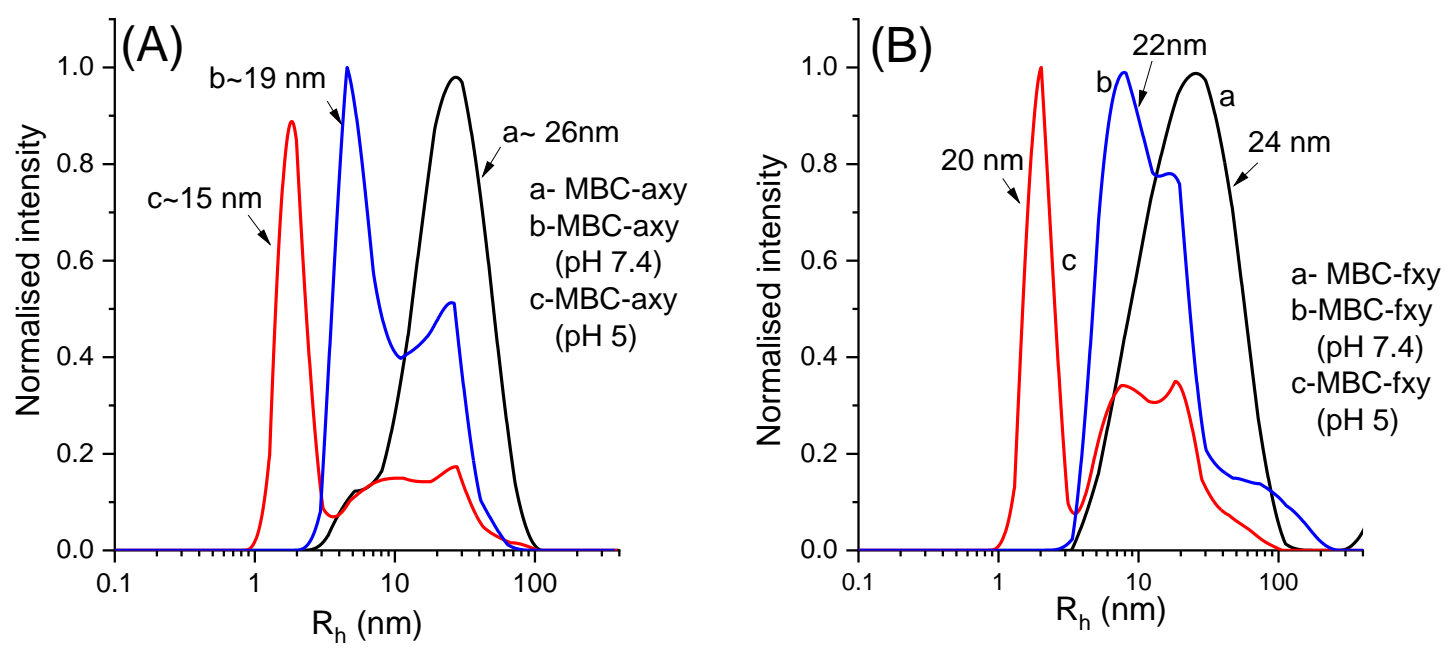

Figure S10. DLS curves of the (A) self-assemblies of MBC-axy, and (B) MBC-fxy before and after incubation at $\mathrm{pH} 7.4$, and $\mathrm{pH} 5$ for 5 days at $37^{\circ} \mathrm{C}$. 


\section{Loading Efficiency and the Environment of Pyrene in the Self-assembly of the Masses of MBC-axy and MBC-fxy Obtained after Hydrolytic Degradation}

The lyophilized masses of the representative MBCs obtained after incubation at $\mathrm{pH} 5$ were utilized to entrap pyrene. The recovered masses were dissolved in DMF and pyrene was added into it. Next, the solutions were subjected to dialysis to remove DMF as described in the main text. The UV-Visible and fluorescence spectra were then recorded to evaluate the loading efficiency of the self-assembly of the MBCs (after hydrolytic degradation) and the environment of pyrene in the self-assembly.
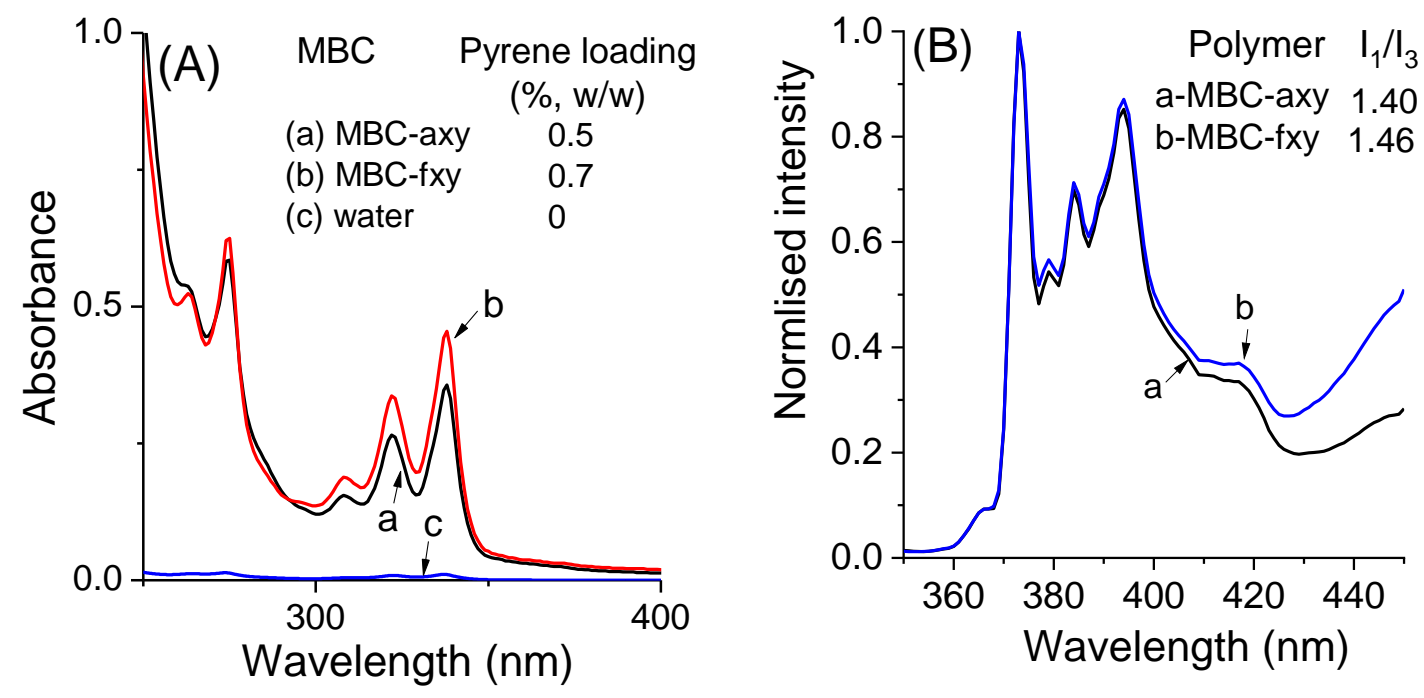

Figure S11. (A) UV-visible, and (B) fluorescence spectra of pyrene encapsulated in the selfassemblies of the masses of MBC-axy and MBC-fxy obtained after incubation at pH 5 and at temperature $37^{\circ} \mathrm{C}$ for 5 days. 
Table S1. Mathematical Models Fitted Data of In Vitro Release of 5-Flurouracil from MBCaxy and MBC-fxy Micelles at $\mathrm{pH} 7.4$ and 5 respectively.

\begin{tabular}{|c|c|c|c|c|c|c|c|c|c|c|c|}
\hline \multirow[t]{2}{*}{$\mathrm{MBC}$} & \multirow[t]{2}{*}{$\begin{array}{l}\text { Release } \\
\text { condition }\end{array}$} & \multicolumn{2}{|c|}{ *Zero Order } & \multicolumn{2}{|c|}{ *First order } & \multicolumn{2}{|c|}{$\begin{array}{l}\text { *Higuchi } \\
\text { Model }\end{array}$} & \multicolumn{2}{|c|}{$\begin{array}{c}\text { *Korsmeyar } \\
\text { Peppas }\end{array}$} & \multicolumn{2}{|c|}{$\begin{array}{l}* \text { Hixon } \\
\text { Crowell }\end{array}$} \\
\hline & & $\mathrm{R}^{2}$ & Slope & $\mathrm{R}^{2}$ & Slope & $\mathrm{R}^{2}$ & Slope & $\mathrm{R}^{2}$ & Slope & $\mathrm{R}^{2}$ & Slope \\
\hline $\begin{array}{l}\text { MBC- } \\
\text { axy }\end{array}$ & $\mathrm{pH} 7.4$ & 0.889 & 0.228 & 0.902 & -0.001 & 0.951 & 2.348 & 0.873 & 0.481 & 0.898 & -0.003 \\
\hline $\begin{array}{l}\text { MBC- } \\
\text { axy }\end{array}$ & $\mathrm{pH} 5$ & 0.558 & 0.726 & 0.687 & -0.007 & 0.836 & 8.829 & 0.963 & 0.531 & 0.636 & -0.018 \\
\hline $\begin{array}{l}\text { MBC- } \\
\text { fxy }\end{array}$ & pH 7.4 & 0.575 & 0.347 & 0.605 & -0.001 & 0.849 & 4.193 & 0.969 & 0.527 & 0.959 & -0.006 \\
\hline $\begin{array}{l}\text { MBC- } \\
\text { fxy }\end{array}$ & $\mathrm{pH} 5$ & 0.813 & 0.559 & 0.907 & -0.003 & 0.977 & 6.091 & 0.985 & 0.48 & 0.878 & -0.011 \\
\hline
\end{tabular}




\section{References}

1. Zhang, B.; Zhang, H.; Li, Y.; Hoskins, J. N.; Grayson, S. M. Exploring the effect of amphiphilic polymer architecture: synthesis, characterization, and self-assembly of both cyclic and linear poly(ethylene gylcol)-b-polycaprolactone. ACS Macro Lett. 2013, $2,845-848$.

2. Chandel, A. K. S.; Nutan, B.; Raval, I. H.; Jewrajka, S. K. Self-assembly of partially alkylated dextran-graft-poly [(2-dimethylamino) ethyl methacrylate] copolymer facilitating hydrophobic/hydrophilic drug delivery and improving conetwork hydrogel properties. Biomacromolecules 2018, 19, 1142-1153.

3. Ghosh, S.; Irvin, K.; Thayumanavan, S. Tunable disassembly of micelles using a redox trigger. Langmuir 2007, 23, 7916-7919.

4. Kumar, A.; Nutan, B.; Jewrajka, S. K. Stability and acidic pH-mediated leakage of guest molecules from self-assembly of poly(amidoamine)-graft-alkyl copolymers. Polymer 2019, 183, 121894.

5. Zhang, Y.; Zhuo, R. X. Synthesis and in vitro drug release behavior of amphiphilic triblock copolymer nanoparticles based on poly(ethylene glycol) and polycaprolactone. Biomaterials 2005, 26, 6736-6742.

6. Dan, K.; Ghosh, S. One-Pot Synthesis of an Acid-Labile Amphiphilic Triblock Copolymer and its pH-Responsive Vesicular Assembly. Angew. Chem., Int. Ed. 2013, $52,7300-7305$. 